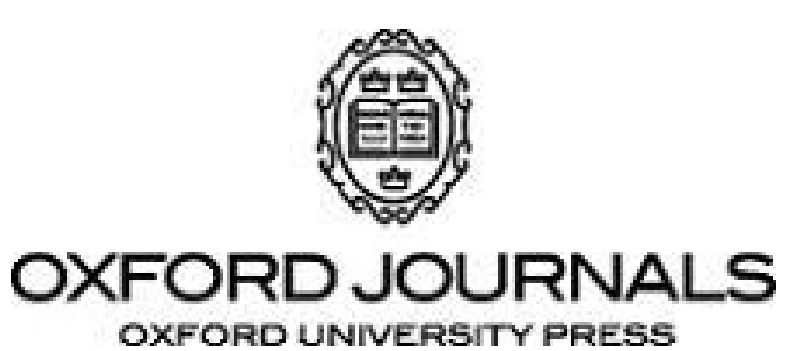

The Review of Economic Studies Ltd.

Unemployment Equilibrium with Myopic Complete Information

Author(s): Walter Perrin Heller and Ross M. Starr

Source: The Review of Economic Studies, Vol. 46, No. 2 (Apr., 1979), pp. 339-359

Published by: Oxford University Press

Stable URL: http://www.jstor.org/stable/2297056

Accessed: 19/07/2011 18:03

Your use of the JSTOR archive indicates your acceptance of JSTOR's Terms and Conditions of Use, available at http://www.jstor.org/page/info/about/policies/terms.jsp. JSTOR's Terms and Conditions of Use provides, in part, that unless you have obtained prior permission, you may not download an entire issue of a journal or multiple copies of articles, and you may use content in the JSTOR archive only for your personal, non-commercial use.

Please contact the publisher regarding any further use of this work. Publisher contact information may be obtained at http://www.jstor.org/action/showPublisher?publisherCode=oup.

Each copy of any part of a JSTOR transmission must contain the same copyright notice that appears on the screen or printed page of such transmission.

JSTOR is a not-for-profit service that helps scholars, researchers, and students discover, use, and build upon a wide range of content in a trusted digital archive. We use information technology and tools to increase productivity and facilitate new forms of scholarship. For more information about JSTOR, please contact support@ jstor.org. 


\title{
Unemployment Equilibrium with Myopic Complete Information
}

\author{
WALTER PERRIN HELLER \\ University of California, San Diego \\ and \\ ROSS M. STARR \\ University of California, Davis
}

\section{INTRODUCTION}

We will demonstrate that unemployment equilibrium can arise (even at Walrasian equilibrium prices) when each non-cooperative optimizing agent has full information about the consequences of his actions. ${ }^{1}$ Agents may be unable to trade all they wish at going market prices because of insufficient demand for goods they want to sell (or insufficient supply for goods they wish to buy). Both in and out of equilibrium, each agent is assumed to know the actual trade possibilities open to him, conditional upon the actions of other agents remaining constant. This degree of information will be called myopic complete information. ${ }^{2}$ Our interest in endowing agents with this much information is that unemployment is less surprising when agents have pessimistic expectations about their trading possibilities. Unemployment in this paper is not due to underestimates (by firms) of demand for output, nor does the presence of unemployment depend on underestimation (by workers) of income.

We make the polar assumption that quantities rather than prices adjust when a market does not clear. Later on, we argue that for some plausible disequilibrium dynamics, there is no pressure on prices at some equilibria. We also exhibit examples of unemployment equilibrium at Walrasian equilibrium prices. Thus, unemployment is not merely the result of rigid prices set at the "wrong" levels.

Studies of unemployment equilibrium face a persistent difficulty in specifying the character of individual optimization. The sticky points include (i) whether quantity constraints on individual purchases and sales implied by the failure of markets to clear are taken as rigid or subject to manipulation by agents' actions; (ii) whether the quantity constraints and the more conventional budget and non-negativity constraints apply to agents' offers (which may not be fulfilled) or to realized trades; (iii) whether offers (which may not be realized) to trade a commodity represent an optimization with respect to that commodity alone (a partial disequilibrium calculation) or an optimization with respect to all goods (general disequilibrium). The view we take in the present study is that budget and nonnegativity constraints apply directly only to actual trades, not to offers. Agents in the market have a rather good idea of what trade will be realized from offers they make. Offers are made after calculation with respect to all markets at once. That is, an offer for a good is made in light of other offers for its substitutes, complements, and other goods (if any) related to it through preferences or the allocation mechanism.

Several authors have demonstrated the existence of unemployment equilibrium in a decentralized economy with optimizing agents (Glustoff (1968), Benassy (1975), Drèze (1975), Grandmont-Laroque (1976), and Hahn (1978)). Walrasian equilibrium with 
involuntary unemployment is a contradiction, of course. Here, a situation is called an equilibrium when the system is at rest and it is in no one's self-interest to alter his behaviour. For comparison, consider the Walras-Arrow-Debreu economy. A price vector is exogenously announced, each agent takes prices as given and freely chooses quantities to buy and sell (being careful not to violate his budget constraint). The resulting excess demand vector is communicated to the market as the agent's intended purchases and sales. Only at equilibrium prices, however, are these intentions realized. If the economy suffers disequilibrium prices, agents' offers to the market are refused, and they are rationed. Thus, in the WalrasArrow-Debreu economy, agents do not possess correct information about the consequences of their actions. Every individual behaves as if his offer will be accepted, an ill-founded supposition at disequilibrium prices.

We postulate a deterministic market allocation mechanism which relates an individual agent's purchase and sales offers (i.e. his signal to the market) to his actual allocations from the market, conditional upon the offers every other agent has made to the market. Agents do not necessarily know the actions of other agents nor do they know the whole allocation mechanism. Each agent does know what allocation he will receive upon making any offer, given the offers of other agents. Agents suppose that the actions of other agents are unchanging. Only in equilibrium are they correct in this supposition of constancy.

Based on this limited knowledge, agents make offers so as to maximize the utility of the allocation actually received. In the language of decision theory, the offers represent actions of the agent and the actual allocations are the consequences of those actions. Concretely speaking, this framework can capture three important phenomena: first, that in attempting to gain employment workers may offer to supply labour on several different labour markets in amounts that are impossible to supply simultaneously; second, that if there is rationing in the aerospace engineer labour market, an agent endowed with this skill may instead offer his services on the lower-paying car mechanic labour market; third, that workers who foresee underemployment cut back on consumption expenditures and saving.

As mentioned earlier, we assume that quantities adjust rather than prices, so that any announced price vector is a candidate for equilibrium. We justify this "Keynesian assumption" on the grounds that in an economy with decentralized agents who take prices as given and choose quantities, it is of interest to examine the possibility of equilibrium in the polar case in which quantities adjust in response to rationing. Since the relationship between offers and allocations is correctly perceived by the individuals, such an equilibrium will be termed a myopic complete information equilibrium (MCI equilibrium). The opposite pole is the well-worked-out neoclassical model in which prices adjust in response to excess Walrasian demand.

Nonetheless, a plausible dynamics of disequilibrium adjustment would be that prices change if there is a perceived excess demand or supply on some markets. We demonstrate that there are non-Walrasian equilibria in which there is no apparent market imbalance to put pressure on prices, even though there is market imbalance in the Walrasian sense. Such equilibria are called strong $\mathrm{MCI}$ equilibria.

The plan of the analysis is first to study market allocation mechanisms in Section 2. In Sections 3 and 4 we take up the analysis of individual choice of households and firms. Equilibrium concepts and existence results are discussed in Section 5. A class of examples is exhibited in Section 6 in which there is a continuum of strong MCI unemployment equilibria even at Walrasian equilibrium prices.

Section 7 discusses relationships between this paper and the literature in some detail, while Section 8 presents the technicalities.

\section{MARKET ALLOCATION MECHANISMS}

Individual agents are either households or firms. We suppose that there are a total of $m$ agents and $n$ commodities plus " money" which is taken to be the numéraire. The only 
role of money in the model is that it is never rationed. Prices are denoted by the vector $p$. Agent $i$ submits to the market a vector of offers to buy and sell, $\tilde{z}_{i}$. Offers that are not credible are rejected by the market and are inadmissible. The net trade offers $\tilde{z}_{i}$ must therefore belong to a set $K_{i}$, the set of credible offers (see further discussion below). After all offers have been made, the allocation $z_{i}$ is made to agent $i$. The allocation for each $i$ is made on the basis of the market allocation function, $F_{i}, z_{i}=F_{i}\left(\tilde{z}_{1}, \tilde{z}_{2}, \ldots, \tilde{z}_{i}, \ldots, \tilde{z}_{m}\right)$.

The constellation of all agents' offers to the market is represented by the $m n$ vector $\tilde{Z}=\left(\tilde{z}_{1}, \tilde{z}_{2}, \ldots, \tilde{z}_{i}, \ldots, \tilde{z}_{m}\right)$. Agent $i$ is confronted by a market characterized by the offers of all other agents:

$$
\tilde{Z}_{i}=\left(\tilde{z}_{1}, \tilde{z}_{2}, \ldots, \tilde{z}_{i-1}, \tilde{z}_{i+1}, \ldots, \tilde{z}_{m}\right),
$$

i.e. the vector of all offers except his own. We may then write more compactly:

$$
z_{i}=F_{i}\left(\tilde{z}_{i}, \tilde{Z}_{i}\right) \text {, with } \tilde{Z}_{i} \text { given to agent } i,
$$

or even more compactly:

$$
z_{i}=F_{i}(\tilde{Z})
$$

The offers $\tilde{z}_{i}$ are made to the market. By "the market" we mean a mechanism (including specialized agents of whom no explicit account is taken) which allocates the aggregate of offers on the short side across the agents on the long side. In a model taking explicit account of price dynamics, the marketing agents would also have a role in price adjustment. Price adjustment is discussed in Sections 5 and 6 . The quantity restrictions that come out of this allocation process are summarized by the market allocation function $F(\widetilde{Z})$. This process is influenced by a number of factors which we will not examine in detail. These include the information structure available to each agent, the societal rules and regulations governing economic distribution and the economic objectives of agents who operate market activities.

Before taking up our general analysis of market allocation mechanisms, let us consider an important special case, that of proportional rationing. Consider a vector of offers by all agents. The aggregate offer for commodity $j$ is

$$
\tilde{z}^{j} \equiv \sum_{i=1}^{m} \tilde{z}_{i j}
$$

If $\tilde{z}^{j}>0$, then there is an excess demand for $j$. If agent $i$ is a demander, then $i$ is said to be on the long side of the market. Similarly, if $\tilde{z}^{j}<0$ and $\tilde{z}_{i j}<0$, then $i$ is also on the long side. Let $L_{j}=\left\{i \mid \tilde{z}_{i j} \tilde{z}^{j}>0\right\}$ be the set of agents on the long side. The complement of $L_{j}$ is called the short side and is denoted $S_{j}$.

The proportional rationing mechanism allocates the available short offers across the agents on the long side in direct proportion to the size of the offer:

$$
z_{i j}=\frac{\tilde{z}_{i j}}{\sum_{k \in L_{j}} \tilde{z}_{k j}}\left(-\sum_{k \in S_{j}} \tilde{z}_{k j}\right) \quad \text { if } i \in L_{j} \text {. }
$$

All those on the short side are allocated precisely what they offered: $z_{i j}=\tilde{z}_{i j}$ if $i \in S_{j}$. Note that at most one side of the market is rationed, and that the sum across agents of the $z_{i j}$ is zero. The functions $F_{i j}$ defined by proportional rationing are continuous, and, for given $\tilde{Z}_{i}$, each $F_{i j}$ is strictly increasing and quasi-concave in $\tilde{z}_{i j}$ and has a continuous inverse function $\tilde{z}_{i j}=F_{i j}^{-1}\left(z_{i}, \tilde{Z}_{i}\right)$. In addition, let $F_{i}\left(K_{i}, \widetilde{Z}_{i}\right)=\left\{z_{i} \mid\right.$ there exists $\tilde{z}_{i} \in K_{i}$ with $\left.z_{i}=F_{i}\left(\tilde{z}_{i}, \tilde{Z}_{i}\right)\right\}$ be the set of allocations possible under the rationing mechanism. One can show that if $K_{i}$ is a cube, then $F_{i}\left(K_{i}, \widetilde{Z}_{i}\right)$ is convex for each $\widetilde{Z}_{i}$, where $F_{i}$ is the proportional rationing function (cf. Assumption M.3 below). These will be useful properties for our analysis.

The proportional case also highlights the importance of making credible offers. Those on the long side individually find it to their advantage to exaggerate the sizes of their offers since they can come closer to their desired allocations. Without a bound imposed by credibility, those on the long side would all be making infinite offers. What is needed is 
a model that explicitly balances the incentives for lying against the consequences of not being believed. Our approach here is to restrict the agents' offers to a compact convex set $K_{i}$. In this way we have attempted to capture the fact that offers to purchase or sell which are "too large" are dismissed out of hand as offers that cannot conceivably be fulfilled. If $p \gg 0$, then $K_{i}$ could be taken as the set of actual net trades consistent with budget constraints. ${ }^{3}$ This would require agents to offer only those trades that they are able to execute.

The assumption of compactness of $K_{i}$ is both a technical necessity and an attempt to capture an element of the behaviour of actual uncleared markets. Arbitrarily large offers are not generally observed. Making offers is itself a costly process involving queuing, telephoning, correspondence, postage and so forth. Further, there is a point to the argument that some offers are too large to be taken seriously. Though the paper studies directly only equilibrium positions, compact $K_{i}$ make particularly good sense out of equilibrium. Prospective sellers need a means to discount or reject purchase offers that would prove false if acted upon. Prospective buyers require similar protection against vacuous offers to sell. Though not foolproof, such protection is provided in part by a policy of simply rejecting excessively large offers. No household with a finite endowment can sustain an arbitrarily large level of trades consistent with budget constraint when prices are strictly positive. An offer to make such a trade is necessarily regarded as incredible by the market. Though arbitrarily large vectors may appear in firm technology sets, and may even promise handsome profits, they do not represent feasible productions in a world of finite resource endowment. A firm's arbitrarily large trade offer is hence equally incredible.

An additional example of a market allocation mechanism is useful: the hierarchic rationing mechanism. Consider a seniority system (or hierarchy) among agents, perhaps varying with the commodity. The short side of the market fulfils its offers completely. On the long side those agents high in the hierarchy fulfil their offers as well. Those agents low in the ranking achieve no trade. Some intermediate agent achieves partial fulfilment to the extent allowed by the amount of the good on the short side and the trades offered by the senior agents. Under the hierarchic rationing mechanism, no agent has an incentive to make an offer in excess of his desired trade, since he cannot thereby force the resulting trade closer to the desired level.

It would certainly be worrying if the relatively arbitrary specification of $K_{i}$ had significant impact on the existence or character of unemployment equilibria. Though examples of this sensitivity are not hard to find, it is fortunately not generally the case. For example, allocations under the hierarchic rationing mechanism are independent of $K_{i}$, so long as allocations are budget-constrained and $K_{i}$ contains all budget-constrained offers. In the "strong" equilibria shown to exist in Theorem 2, and constructed as examples in Section 6, offers and realized trades coincide. The constraint that $\tilde{z}_{i} \in K_{i}$ then is redundant, and is certainly not binding for $K_{i}$ large. In this family of cases, and we expect more generally as well, the specification of $K_{i}$ (when large relative to sustainable trades) has no effect on the equilibrium allocation. We will see below that the presence of unemployment in equilibrium is not simply ascribable to a small $K_{i}$. Rather, unemployment may come about because the range of $F_{i}\left(\cdot, \widetilde{Z}_{i}\right)$ is restricted by the specified $\widetilde{Z}_{i}$. Even when agent $i$ 's offers are not effectively restricted by $K_{i}$, he may not wish to issue bigger offers; this happens because, given other agents' offers, calling out larger offers would not result in a more desirable trade to $i$. Section 6 below illustrates the point.

Conversely, it is possible to construct examples (e.g. in the case of the proportional rationing mechanism) where agents tend to make offers as large as they are allowed in order to achieve a relatively large allocation of a good in short supply or to sell a relatively large amount of a good in excess supply. In that case agents' offers will be on the boundary of $K_{i}$; the existence of an equilibrium requires the compactness of $K_{i}$; and the allocation that results depends in part on $K_{i}$ 's specification. However, consider for the moment the special 
case where the $K_{i}$ consist of just those offers that are possible for the agent to carry out (e.g. satisfy the budget constraint). It is still true that the equilibrium position depends on the specification of the $K_{i}$, but it is entirely natural that the equilibrium allocation depend on the actual trading possibilities open to agents. Moreover, it is particularly evident in the case that $K_{i}$ is identical to the budget set that there is a cost to the agent of exaggerating an offer; viz. the inability to make sincere and desirably large offers on other markets.

It would be of interest to know when the assumption that $K_{i}$ be compact (for all $i$ ) is superfluous. In that case we could be sure that the MCI equilibrium allocations were independent of boundedness restrictions on the $K_{i}$. Though general sufficient conditions for this independence have not been established, there are some satisfactory examples. The essential point is to arrange the allocation mechanism so that optimizing offers stay within a bounded set even without a restriction to $K_{i}$. The hierarchic mechanism fulfils this property. Other mechanisms consistent with this aim will be those (unlike the proportional rationing mechanism) that are unresponsive to large and overstated offers. One such mechanism is a hierarchic mechanism with endogenous hierarchy. In this allocation function the short side is allotted precisely what it offers. Offers on the long side are arranged in order of size, smallest (in absolute value) first (a tie-breaking rule is of course needed). They are then fulfilled, within the limits of available short side offers, in that order. No agent actually seeking to trade on the long side will overstate his offer beyond a genuinely desired level. There may be some purposeful understatement. In this situation, restriction of offers to compact $K_{i}$ is redundant. Conditions usefully generalizing this property are still needed.

The first assumption is that the set of admissible (or credible) offers $K_{i}$ is a compact convex set. The no-trade offer is in the interior of $K_{i}$, a harmless but very useful assumption.

Assumption M.1. For all $i$, trade offers $\tilde{z}_{i}$ must belong to the credible offer set $K_{i}$, where $K_{i}$ is a compact convex subset of $R^{n}$ and $0 \in$ int $K_{i}$.

Remark. If prices are strictly positive, a special case of this assumption is that $K_{i}$ consist only of those offers that could actually be carried out (i.e. satisfy budget and endowment constraints, see below). This is a useful interpretation of credibility, but it is rather more stringent than one experiences in the market-place. We prefer to allow, as credible, offers that cannot be fulfilled.

The next assumption asserts that the market allocation mechanism is continuous, so that neighbouring offers lead to neighbouring allocations. Also, the no-trade allocation is always obtainable by offering nothing in trade.

Assumption M.2. For all $i, F_{i}\left(\tilde{z}_{i}, \widetilde{Z}_{i}\right): R^{m n} \rightarrow R^{n}$, is a continuous function such that for any $\widetilde{Z}_{i}, F_{i}\left(0, \widetilde{Z}_{i}\right)=0$.

The third hypothesis on the structure of the market allocation mechanism plays the role in the proofs of continuity below that is usually played by convexity. The inverse image correspondence is defined as $F_{i}^{-1}\left(A, \tilde{Z}_{i}\right)=\left\{\tilde{z}_{i} \mid F_{i}\left(\tilde{z}_{i}, \tilde{Z}_{i}\right) \in A\right\}$ and we also write $F^{-1}\left(z_{i}, \widetilde{Z}_{i}\right)=\left\{\tilde{z}_{i} \mid z_{i}=F_{i}\left(\tilde{z}_{i}, \widetilde{Z}_{i}\right)\right\}$.

Assumption M.3. (a) $F_{i}^{-1}\left(z_{i}, \widetilde{Z}_{i}\right)$ is a convex set for any $\left(z_{i}, \tilde{Z}_{i}\right)$; (b) $F_{i}\left(K_{i}, \tilde{Z}_{i}\right)$ is convex for all $\widetilde{Z}_{i}$.

Assumption M.3 states that the set of offers leading to a given allocation is convex, conditional upon $\widetilde{Z}_{i}$ and that given $\widetilde{Z}_{i}$ any convex combination of allocations in the range of $F_{i}\left(\cdot, \widetilde{Z}_{i}\right)$ is realizable by a credible offer in $K_{i}$. One can show that a sufficient condition for Assumption M.3b is that $K_{i}$ be a cube and $F_{i}$ be monotone increasing in $\tilde{z}_{i}$ and "independent" in the sense that given $\widetilde{Z}_{i}$ the allocation for commodity $j, z_{i j}$, depends only upon the offer $\tilde{z}_{i j}$ (providing, however, that Assumptions M.1, M.2 and M.4 (below) also hold). In Assumption M.3a convexity could be replaced by the weaker condition of contractibility. A set is contractible if it is continuously deformable to a point in the set (see Debreu (1952) and the Appendix to this paper for details). 
There are several justifications for the convexity of $F_{i}\left(K_{i}, \tilde{Z}_{i}\right)$. We have already indicated that if the allocation mechanism is independent and the $K_{i}$ are hypercubes, then $F_{i}\left(K_{i}, \widetilde{Z}_{i}\right)$ is convex. But what if the only credible offers are those in the budget set $B_{i}$ ? One can show that if $F_{i}\left(\tilde{z}_{i}, \widetilde{Z}_{i}\right)$ is concave and monotonic in $\tilde{z}_{i}$, then $F_{i}\left(B_{i}, \widetilde{Z}_{i}\right)$ is convex. But concavity is not satisfied, for example, by the proportional rationing mechanism, which is concave for $\tilde{z}_{i} \geqq 0$ and convex for $\tilde{z}_{i} \leqq 0$.

Even when the opportunity set $F_{i}\left(B_{i}, \widetilde{Z}_{i}\right)$ is not convex, an agent will have continuous demand functions under the following conditions: (i) the allocation is such that each agent at an optimum is rationed, if at all, on the same side of every market (i.e. if the agent is rationed on a market in which he is a buyer (seller), then he is not rationed on any market in which he is a seller (buyer)). (ii) the market allocation mechanism is "one-sided" (at most one side of any market is rationed; see Assumption M.6), (iii) objective functions are strictly quasi-concave. ${ }^{4}$

The next hypothesis of this section requires that, conditional upon $\tilde{Z}_{i}$, the agent can move in any direction away from his current trade $z_{i}^{0}$ by making an arbitrarily small movement away from his current offer $\tilde{z}_{i}^{0}$, whenever there is some (large?) movement in $\tilde{z}_{i}$ that would change $z_{i}$ in that direction. We call this local responsiveness of the market allocation mechanism. In the statement of Assumption M.4 below, one should think of $z_{i}^{0}$ as a current trade derived from the offer $\tilde{z}_{i}^{0}$ and $z_{i}^{1}$ as an alternative possible trade derived from $\tilde{z}_{i}^{1}$. The line segment $\left[z_{i}^{0}, z_{i}^{1}\right]$ represents a direction of change. Assumption M.4 then states that the final trade can be moved in the direction of $z_{i}^{1}$ by making some arbitrarily small movement away from the offer $\tilde{z}_{i}^{0}$.

Assumption M.4. (Local Responsiveness.) Let $z_{i}^{0}=F_{i}\left(\tilde{z}_{i}^{0}, \tilde{Z}_{i}\right)$ and $z_{i}^{1}=F_{i}\left(\tilde{z}_{i}^{1}, \tilde{Z}_{i}\right)$, where $z_{i}^{0} \neq z_{i}^{1}$. Then, for every neighbourhood $N\left(\tilde{z}_{i}^{0}\right)$ of $\tilde{z}_{i}^{0}$, there exists $\tilde{z}_{i} \in N\left(\tilde{z}_{i}^{0}\right)$ and a $\lambda$ such that $0<\lambda<1$ and $F_{i}\left(\tilde{z}_{i}, \tilde{Z}_{i}\right)=(1-\lambda) z_{i}^{0}+\lambda z_{i}^{1}$.

The next condition is that of market balance of allocations. Rationing arises in response to market imbalance, and practically by definition whatever good is actually acquired by one agent has been relinquished by another. An exception to this might be thought to arise if there were stocks held over from previous periods, but even in this case, such stocks are held by some agent who gives them up at the going price.

Assumption M.5. $\sum_{i=1}^{m} F_{i}(\tilde{Z})=0$, all $\tilde{Z}$.

The last condition is that of one-sideness, viz. only one side of any market is rationed. This property arises in the non-tâtonnement stability literature (Hahn-Negishi (1962)) and is the embodiment of the notion that actual trade equals the lesser of supply and demand. We impose this condition so as to ensure that the allocation mechanism allows people to trade if there is some expressed desire to do so on both sides of any market.

Assumption M.6. The allocation mechanism $F$ is one-sided, i.e.

(i) $\sum_{i=1}^{m} \tilde{z}_{i j}<0$ implies $F_{i j}(\tilde{Z}) \geqq \tilde{z}_{i j}$ and $F_{i j}(\tilde{Z})=\tilde{z}_{i j}$ when $\tilde{z}_{i j}>0$, i.e. if there is aggregate excess supply, then only suppliers are rationed.

(ii) $\sum_{i=1}^{m} \tilde{z}_{i j}>0$ implies $F_{i j}(\tilde{Z}) \leqq \tilde{z}_{i j}$ and $F_{i j}(\tilde{Z})=\tilde{z}_{i j}$ when $\tilde{z}_{i j}<0$, i.e. if there is aggregate excess demand, then only demanders are rationed.

The proportional and hierarchic rationing mechanisms are particular cases that satisfy M.1-M.6, so long as $K_{i}$ is bounded for all $i$.

\section{INDIVIDUAL HOUSEHOLD DECISIONS}

Individual households are denoted with the subscript $i$ where $i \in H$ and $H$ is the set of all households. They possess the utility function $U_{i}$, an endowment $\omega_{i} \in R_{+}^{n}$ of commodities, 
$\bar{M}_{i} \geqq 0$ of money and a non-negative fraction $\alpha_{i f}$ of the dividends $d_{f}$ of firm $f$. Any allocation possible for the household must satisfy the budget constraint:

$$
p z_{i}+M_{i} \leqq \bar{M}_{i}+\sum_{f \in F} \alpha_{i f} d_{f},
$$

where $p, \bar{M}_{i}, \alpha_{i f}$ and $d_{f} \geqq 0$ for $f \in F$ are given to the household, and where $F$ is the subset of firms and $M_{i}$ denotes the quantity of money the household wishes to hold.

A word should be said about money in the utility function. As emphasized by Grandmont (1974), money held at the end of the current period can be rationalized by a multiperiod utility function in a model where money is a store of wealth in an uncertain world. Thus, a single period utility function with money can be derived in the fashion of dynamic programming from optimization over future periods. With this interpretation in mind, we will write $U_{i}=U_{i}\left(\omega_{i}+z_{i}, M_{i}\right)$, where $U_{i}$ is defined over the set of admissible consumption vectors, $C_{i}$ and the set of possible money holdings $R_{+}$. Thus,

$$
\left(\omega_{i}+z_{i}\right) \in C_{i} \text {, where } \omega_{i} \text { and } C_{i} \text { are given, and } M_{i} \geqq 0 \text {. }
$$

Define $B_{i}(d)$ to be the set of possible trades (satisfying (3.1) and (3.2)) where $d=\left(d_{f}\right)$ :

$$
B_{i}(d)=\left\{z_{i} \mid \omega_{i}+z_{i} \in C_{i} \text { and } \sum_{f \in F} \alpha_{i f} d_{f}+\bar{M}_{i}-p z_{i} \geqq 0\right\} .
$$

We suppose that $C_{i}$ is bounded below and that either prices are strictly positive or that $C_{i}$ is bounded above in those components for which $p_{i}=0$. Thus $B_{i}(d)$ is compact.

The conditions on offers are that they be credible (cf. Section 2 for discussion):

$$
\tilde{z}_{i} \in K_{i} \text {, where } K_{i} \text { is given. }
$$

We also insist that final allocations are those obtained via the market allocation mechanism:

$z_{i}=F_{i}\left(\tilde{z}_{i}, \tilde{Z}_{i}\right)$, where $\tilde{Z}_{i}$ is the given vector of offers made by other agents.

The individual household's aim is then to maximize $U_{i}\left(\omega_{i}+z_{i}, M_{i}\right)$ with respect to $\tilde{z}_{i}$, subject to the constraints (3.1)-(3.4).

We shall suppose that $U_{i}$ satisfies local non-satiation and that money is not undesirable. Since money is not rationed, we may without loss of generality write the budget constraint (3.1) as an equality, for in so doing we do not deny the agent any opportunity that is preferred to those remaining. With this understanding, define

$$
S_{i}\left(\tilde{Z}_{i}, d\right) \equiv\left\{\tilde{z}_{i} \in K_{i} \mid F_{i}\left(\tilde{z}_{i}, \tilde{Z}_{i}\right) \in B_{i}(d)\right\} \equiv F_{i}^{-1}\left(B_{i}(d), \tilde{Z}_{i}\right) \cap K_{i}
$$

as the set of all offers that are possible for household $i$ (i.e. satisfy (3.1)-(3.4)).

Let $V_{i}\left(\tilde{z}_{i}, \tilde{Z}_{i}, d\right)$ stand for the utility that can be obtained from the market allocation mechanism when the offer $\tilde{z}_{i}$ is chosen, conditional upon the offers of the other agents, $\tilde{Z}_{i}, d$. Thus,

$$
V_{i}\left(\tilde{z}_{i}, \widetilde{Z}_{i}, d\right) \equiv U_{i}\left[F_{i}\left(\tilde{z}_{i}, \tilde{Z}_{i}\right)+\omega_{i}, \sum \alpha_{i f} d_{f}+\bar{M}_{i}-p F_{i}\left(\tilde{z}_{i}, \tilde{Z}_{i}\right)\right]
$$

The individual household's problem can now be restated as:

$$
\text { Choose } \tilde{z}_{i} \text { to maximize } V_{i}\left(\tilde{z}_{i}, \tilde{Z}_{i}, d\right) \text { subject to } \tilde{z}_{i} \in S\left(\tilde{Z}_{i}, d\right) \text {. }
$$

We denote the set of solutions to (7) by $\gamma_{i}\left(\tilde{Z}_{i}, d\right)$. In order to obtain upper hemicontinuity of $\gamma_{i}\left(\tilde{Z}_{i}, d\right)$, we will require Assumptions H.1 and H.2 below.

The first assumption is more or less standard except that we require strict quasiconcavity of $U_{i}$ in order to simplify the discussion.

Assumption H.1. For all $i \in H, U_{i}: C_{i} \times R_{+} \rightarrow R$ is a continuous and strictly quasiconcave function that satisfies local non-satiation, where $C_{i}$ is a closed convex set that is bounded from below.

The second assumption is a standard one on the endowment structure of the household. It implies that int $B_{i}(d) \neq \varnothing$.

Assumption H.2. $\omega_{i} \in \operatorname{int} C_{i}$ and $\bar{M}_{i}>0$, for $i \in H$. 
The third assumption is not necessary until Theorem 2 (on the existence of " strong" equilibria). This assumption simply states that any offer that is possible for the household is also credible.

Assumption H.3. $B_{i}(d) \subset K_{i}$ for $i \in H$.

\section{PRODUCTION AGENTS}

Let $F$ denote the subset of all agents that are firms. For $i \in F$, let $X_{i}$ be the production technology, i.e. the set of possible production plans of the firm. Firms possess a preexisting stock of goods, $\omega_{i}$, consisting of capital stocks and inventories. If $z_{i}$ is a net trade vector, then we require that $\omega_{i}+z_{i} \in X_{i}$. Also let $\bar{M}_{i}$ be the pre-existing level of cash holdings. The source of $\bar{M}_{i}$ could be retained earnings, stock sales and so on. We adopt a different sign convention than usual to represent inputs and outputs. A positive level of $z_{i j}$ or $\tilde{z}_{i j}$ means the firm is demanding an input or offering to demand an input, while negative values indicate supply. Thus short run profits are $-p z_{i}$ where $p$ is taken as given. The firm's decision variables are the quantities, $z_{i}$, dividends, $d_{i}$, and cash holdings, $M_{i}$. By definition, cash holdings are what is left over after dividends have been paid out of profits and pre-existing cash: $M_{i}=\bar{M}_{i}-p z_{i}-d_{i}$. Let $Y_{i}$ be firm $i$ 's set of possible net trades, $z_{i}$. For $z_{i} \in Y_{i}, z_{i}+\omega_{i}$ must be an element of $X_{i}$. In addition, we implicitly assume in Assumption F.3 below that $Y_{i}$ is compact. This involves little loss of generality, since under standard assumptions, attainable production plans for the economy, and hence for the individual firm, lie in a compact set.

The firm's intertemporal objectives in the face of limited information and incomplete markets are complex and not completely understood by economists. We wish to incorporate the trade-offs among short-run profits, $-p z_{i}$, inventory holding and capital accumulation (also represented through $z_{i}$ ), dividends and retained earnings. We therefore write the objective function as $U_{i}\left(-z_{i}, M_{i}, d_{i}\right)$. It represents the reduced form of the firm's intertemporal maximization problem, since prices are fixed.

The constraints on the firm include the market allocation function,

the production set,

$$
z_{i}=F_{i}\left(\tilde{z}_{i}, \tilde{Z}_{i}\right)
$$

the cash and dividend constraints,

$$
z_{i} \in Y_{i}
$$

$$
M_{i} \equiv \bar{M}_{i}-p z_{i}-d_{i} \geqq 0 \quad \text { and } \quad d_{i} \geqq 0 .
$$

The inequalities (3) merely reflect impossibility of negative money holding and limited liability of stockholders.

Since the firm knows the implications of the allocation function, it can-indeed it must - arrange its offer so that the resulting net trade is technically feasible and satisfies the " budget constraint" (4.3). Let $B_{i}\left(d_{i}\right)=\left\{z_{i} \mid z_{i} \in Y_{i}\right.$ and $\left.\bar{M}_{i}-p z_{i}-d_{i} \geqq 0\right\}$. If $Y_{i}$ is compact, so is $B_{i}\left(d_{i}\right)$.

We require that offers be credible (cf. Section 2 for discussion):

$$
\tilde{z}_{i} \in K_{i} \text {. }
$$

Let $G_{i}\left(z_{i}\right) \equiv\left\{d_{i} \mid \bar{M}_{i}-p z_{i} \geqq d_{i} \geqq 0\right\}$ denote the set of possible (i.e. satisfying (4.3)) dividend levels for a given production plan. The conditional opportunity set for the firm is thus:

$$
S_{i}\left(\tilde{Z}_{i}\right) \equiv\left\{\left(\tilde{z}_{i}, d_{i}\right) \mid F_{i}\left(\tilde{z}_{i}, \tilde{Z}_{i}\right) \in Y_{i}, \bar{M}_{i}+p F\left(\tilde{z}_{i}, \tilde{Z}_{i}\right)-d_{i} \geqq 0,\right.
$$

Define $H_{i}\left(z_{i}, \tilde{Z}_{i}\right)=F_{i}^{-1}\left(z_{i}, \tilde{Z}_{i}\right) \times G_{i}\left(z_{i}\right)$. Thus

$$
\left.d_{i} \geqq 0 \text { and } \tilde{z}_{i} \in K_{i}\right\} .
$$

$$
S_{i}\left(\tilde{Z}_{i}\right)=H_{i}\left(Y_{i}, \tilde{Z}_{i}\right) \cap\left(K_{i} \times R_{+}\right) .
$$


We also write $V_{i}\left(\tilde{z}_{i}, d_{i}, \tilde{Z}_{i}\right)=U_{i}\left(-F_{i}\left(\tilde{z}_{i}, \tilde{Z}_{i}\right), \bar{M}_{i}-p F_{i}\left(\tilde{z}_{i}, \tilde{Z}_{i}\right)-d_{i}, d_{i}\right)$. Thus the firm's objective is to:

$$
\text { Choose }\left(\tilde{z}_{i}, d_{i}\right) \text { to maximize } V_{i}\left(\tilde{z}_{i}, d_{i}, \tilde{Z}_{i}\right) \text { subject to }\left(\tilde{z}_{i}, d_{i}\right) \in S_{i}\left(\tilde{Z}_{i}\right) \text {. }
$$

The set of solutions to (4.7) will be denoted $\gamma_{i}\left(\tilde{Z}_{i}\right) \quad(i \in F)$. We shall require several additional assumptions to obtain the needed continuity conditions. The first one has been discussed except that, as in the case of Assumption H.1, strict quasi-concavity is not essential and is assumed for simplicity. The second assumption is straightforward, except that we presume for the sake of technical convenience that $\bar{M}_{i}>0$ and $\omega_{i} \in \operatorname{int} X_{i}$, i.e. that the firm has positive inventory holding of one of its inputs. This clearly implies that $0 \in$ int $Y_{i}$.

Assumption F.1. For all $i \in F, U_{i}\left(-z_{i}, M_{i}, d_{i}\right)$ is a continuous strictly-quasi-concave non-decreasing function of its variables.

Assumption F.2. For all $i \in F, X_{i}$ is a closed convex set with $0 \in X_{i}$ and $X_{i}$ satisfies free disposal. Furthermore $\bar{M}_{i}>0$ and $\omega_{i} \in$ int $X_{i}$.

The third assumption of this section is not necessary until Theorem 2. Analogously with Assumption H.3, it simply requires that any possible offer for the firm is also credible.

Assumption F.3. $\quad B_{i}\left(d_{i}\right) \subset K_{i}$ and $d_{i} \geqq 0$ for $i \in F$.

\section{EQUILIBRIUM ANALYSIS}

The choice of the most appropriate concept of equilibrium in the context of quantity adjustment without price adjustment is a somewhat delicate question. There should certainly be no motive for any agent to move (in a feasible direction) away from his equilibrium choice. This means, among other things, that intentions should be realized. Thus, market balance of final allocations may be a condition of equilibrium for the same reason that it is a condition of Walrasian equilibrium: in its absence, the intentions of some agent would be frustrated so that he would have an incentive to change his actions.

There should also be no pressure on prices in equilibrium. But how can this happen when we are, for the purposes of analysis, fixing prices at levels that are most likely not market-clearing in the Walrasian sense? If the short side of the market for a given commodity happens to be demand (i.e. if the offers to sell exceed the offers to buy), then the price for the commodity tends to fall. In the reverse case, the price tends to rise. Offers are the signals used by the Walrasian auctioneer. Thus one might think it reasonable that a condition of equilibrium be that offers balance out, since otherwise, prices would not be at rest.

However, casual observation may suggest that prices do not move on some markets even when offers are not balanced, viz. labour markets. The rationale given for this circumstance is that firms face a fixed low demand for output and would not hire more labour even at lower wages. Thus there may be no pressure on prices even when $\sum_{i=1}^{m} \tilde{z}_{i} \neq 0$. So we shall examine the existence of such equilibria in the Theorem below. We call these equilibria Myopic Complete Information equilibria (or MCI equilibria).

But it is still of interest to know whether there are equilibria with $\sum_{i=1}^{m} \tilde{z}_{i}=0$. Under the price adjustment process alluded to above, there would surely be no forces acting on prices when offers balance each other. Furthermore, there are good reasons for insisting that offers should actually be executed (i.e. $\tilde{z}_{i}=z_{i}$ ) in equilibrium. If some households or firms are not fulfilling their promises to market agents, then market agents will not trust $\tilde{z}_{i}$ to provide an accurate signal of market conditions. Hence, even if offers balance, market agents may wish to change prices (on the next " round") in cases where $z_{i} \neq \tilde{z}_{i}$. We provide conditions for the existence of "strong" MCI equilibria in Theorem 2 below. 
It remains to formulate precisely our concepts of equilibrium in this economy, show their existence and interpret the results. As discussed earlier, an equilibrium is a rest point of the system, so that once at equilibrium, there is no incentive for any agent to move. This idea is embodied in the Nash equilibrium concept for a generalized game, which we adopt here.

Definition. A Myopic Complete Information Equilibrium is a vector of market offers $\tilde{Z}^{*}$ and dividends $d^{*}$ such that for $i \in H, \tilde{z}_{i}^{*} \in S_{i}\left(\tilde{Z}_{i}^{*}, d^{*}\right)$ and $V_{i}\left(\tilde{z}_{i}^{*}, \tilde{Z}_{i}^{*}, d^{*}\right) \geqq V_{i}\left(\tilde{z}_{i}, \tilde{Z}_{i}^{*}, d^{*}\right)$ for all $\tilde{z}_{i} \in S_{i}\left(\tilde{Z}_{i}^{*}, d^{*}\right)$, while for $i \in F,\left(\tilde{z}_{i}^{*}, d_{i}^{*}\right) \in S_{i}\left(\tilde{Z}_{i}^{*}\right)$ and $V_{i}\left(\tilde{z}_{i}^{*}, d_{i}^{*}, \tilde{Z}_{i}^{*}\right) \geqq V_{i}\left(\tilde{z}_{i}, d_{i}, \tilde{Z}_{i}^{*}\right)$ for all $\left(\tilde{z}_{i}, d_{i}\right) \in S_{i}\left(\tilde{Z}_{i}^{*}\right)$. Lastly, $\sum_{i=1}^{m} F_{i}\left(\tilde{Z}^{*}\right)=0$. (We have not required that $\sum M_{i}=\sum \bar{M}_{i}$, because money market clearing follows from $\sum z_{i}=0$ and household and firm budget constraints.)

A more interesting situation occurs when offers equal actual trades in equilibrium. In such a " strong" equilibrium every agent actually trades exactly what he offers. Thus, the market-presumably consisting of an auctioneer or specialists not explicitly treated herereceives exactly what agents offer. Thus the expectations of all agents are fulfilled. More importantly, there may be no market pressure for price changes. For, suppose the dynamics of price adjustment to be geared to offers, the only market signals available. In a strong equilibrium apparent excess demands are zero, so there is no pressure on prices in a strong equilibrium. The assumption of fixed prices appears less stringent when the model possesses a strong equilibrium.

Definition. A strong MCI equilibrium is an MCI equilibrium in which offers equal actual allocations, $z_{i}^{*}=\tilde{z}_{i}^{*}$, all $i$, and $\sum_{i=1}^{m} \tilde{z}_{i}^{*}=0$.

A strong equilibrium is one in which each agent willingly calls out an offer vector that it actually intends to fulfil. For a typical agent this can occur in two ways. It may be fortunate enough that others' offers $\widetilde{Z}_{i}$ and the allocation function $F_{i}\left(\cdot, \widetilde{Z}_{i}\right)$ do not represent a binding constraint. In this case, its offer and trade are simply the Walrasian excess demand vector. Alternatively, others' offers and the allocation function may impose so rigid a constraint that no variation in the offer beyond the achieved trade calls forth any (desirable) response at all. We exhibit several instances of the latter phenomenon in Section 6 below. In either of these cases, offers and trades will coincide.

Since the zero offer vector may be an equilibrium, and is not interesting, we investigate instead the existence of non-trivial equilibria:

Definition. A non-trivial MCI equilibrium is one in which $z_{i}^{*} \neq 0$ for some $i$, i.e. trade takes place in equilibrium.

We show in Section 8 that all the properties needed to obtain existence of non-trivial MCI equilibrium are satisfied, and we apply Debreu's social equilibrium existence theorem (Debreu (1952)) (see the Appendix for a statement of this theorem).

The trivial offer $(\tilde{Z}, d)=0$ is always an equilibrium when there is market balance $\sum_{i} F_{i}(\widetilde{Z})=0$. To see this, merely note that for all $i$ and $\tilde{z}_{i}$ :

$$
F_{i}\left(\tilde{z}_{i}, 0\right)=-\sum_{k \neq i} F_{k}\left(0, \ldots, \tilde{z}_{i}, 0, \ldots\right)=0,
$$

where the latter equality follows from $F_{k}\left(0, \tilde{Z}_{k}\right)=0$. With one additional assumption, however, a non-trivial equilibrium always exists. Given $\tilde{Z}$, let $B_{j}$ be the set of agents who are buyers of commodity $j\left(\tilde{z}_{i j}>0\right)$ and $S_{j}$ be the set of sellers $\left(\tilde{z}_{i j}<0\right)$.

Assumption T.1. (Desirability of Trade.) ${ }^{5}$ There exists a good $j$, two households $i_{1} \in S_{j}$ and $i_{2} \in B_{j}$, and two small numbers $\varepsilon_{1}, \varepsilon_{2}>0$ such that whenever $\sum_{i \in B_{j}} \tilde{z}_{i j} \geqq \varepsilon_{2}$, then $\tilde{z}_{i_{1}} \in \gamma_{i_{1}}\left(\widetilde{Z}_{i_{1}}, d\right)$ implies $\tilde{z}_{i_{1} j} \leqq-\varepsilon_{1}$. Similarly, if $\sum_{i \in S_{j}} \tilde{z}_{i j} \leqq-\varepsilon_{1}$, then $\tilde{z}_{i_{1}} \in \gamma_{i_{2}}\left(\tilde{Z}_{i_{2}}, d\right)$ implies $\tilde{z}_{i_{2} j} \geqq \varepsilon_{2}$. 
This condition simply states that if one agent is confronted with a selling offer in commodity $j$ of at least $\varepsilon_{1}$ units then it is always to his advantage to make an offer to buy at least $\varepsilon_{2}$ units, while the reverse holds for the other agent. Hence there is a coincidence of wants that can be carried out through the market allocation mechanism. It would be of some interest to derive this condition from more primitive assumptions. It is certainly satisfied, when there is coincidence of wants in one good, by the proportional and hierarchic rationing mechanisms.

Our strategy for obtaining the existence of a non-trivial equilibrium should now be evident. We show existence for the fictitious economy where traders $i_{1}$ and $i_{2}$ are bounded away from zero in the $j$ th good by $\varepsilon_{1}$ and $\varepsilon_{2}$, and then drop the $\varepsilon_{1}$ and $\varepsilon_{2}$ constraints and show that the set of equilibria does not shrink since the constraints imposed by $\varepsilon_{1}$ and $\varepsilon_{2}$ on agents $i_{1}$ and $i_{2}$ were not binding to begin with for those equilibria in the fictitious economy.

Theorem 1. Under Assumptions M.1-M.6, H.1-H.2, F.1-F.2, and T.1 a non-trivial MCI equilibrium exists.

Proof. See Section 8. \|

We introduce the next assumption in order to guarantee the existence of strong equilibria.

Assumption T.2 (Hierarchy in one commodity). Let $i_{1}$ and $i_{2}$ be the same pair of households and $j$ be the same commodity as in Assumption T.1. Given $\widetilde{Z}$, let $S_{j}$ be the set of sellers of $j$ and $B_{j}$ be the set of buyers of $j$. Then $i_{1}$ and $i_{2}$ receive in actual trade precisely what they offer, up to the amount offered on the opposite side of the market, i.e. $F_{i_{1} j}(\tilde{Z})=\max \left(\tilde{z}_{i_{1} j}, \quad-\sum_{k \in B_{j}} \tilde{z}_{k j}\right) \leqq 0$, and $F_{i_{2 j}}(\tilde{Z})=\min \left(\tilde{z}_{i_{2 j} j}, \quad-\sum_{k \in S_{j}} \tilde{z}_{k j}\right) \geqq 0$. Also, $\varepsilon_{1}=\varepsilon_{2}$ in Assumption T.1.

Remarks. If $i_{1}$ and $i_{2}$ are high in the hierarchy of the rationing mechanism (as in, for example, the seniority system in labour contracts), then Assumption T.2 is satisfied. Alternatively, if $i_{1}$ and $i_{2}$ trade directly, so that $\tilde{z}_{i_{1} j}=-\tilde{z}_{i_{2} j}=z_{i_{1} j}=-z_{i_{2} j}$, then Assumption T.2 is also satisfied.

We also need, for the existence of a non-trivial strong equilibrium that $\varepsilon_{1}=\varepsilon_{2}$ in Assumption T.1. This is not unreasonable since it merely requires that some agent be willing to offer at least some small amount $\varepsilon$ if he observes that aggregate offers on the other side of the market are at least $\varepsilon$; the hierarchic rationing mechanism certainly has this property.

Theorem 2. Under Assumptions M.1-M.6, H.1-H.3, F.1-F.3, T.1 and T.2, there exists a non-trivial strong MCI equilibrium.

Proof. See Section 8. ॥

Corollary. An offer vector in a strong equilibrium belongs to $B_{i}\left(d^{*}\right)$.

Proof. The offer $\tilde{z}_{i}^{*}=z_{i}^{*} \in B_{i}\left(d^{*}\right)$ by assumption. $\|$

Remarks. (i) In a strong equilibrium, every agent is "telling the truth". Hence the restriction of offers to the compact convex set $K_{i}$ is not binding, except insofar as $\tilde{z}_{i}^{*} \in B_{i}\left(d^{*}\right)$. If $B_{i}\left(d^{*}\right)$ is contained in the interior of $K_{i}$, then no offer is on the boundary of $K_{i}$.

(ii) The non-triviality property is actually rather limited as stated. For, all we know is that agents $i_{1}$ and $i_{2}$ are trading positive amounts. The other agents might not be trading at all. If agents other than $i_{1}$ and $i_{2}$ satisfy the same properties as asserted in Assumptions T.1 and T.2, an argument similar to that in the proof of Theorem 2 guarantees that they will trade as well. Indeed, if there is a chain of multilateral trade relations 
indirectly linking every pair of households, one may be able to show that every household engages in non-zero trade in a strong equilibrium.

(iii) The hierarchic rationing mechanism satisfies Assumptions M.1-M.6, T.1 and T.2, so Theorem 2 is not vacuous. Note that proportional rationing is ruled out on the jth market by Assumption T.2.

\section{UNEMPLOYMENT}

We have shown that there is a non-trivial MCI equilibrium, but we have not yet shown there is unemployment in this equilibrium. We can interpret unemployment here to mean that there are offers to sell labour which do not balance out in the aggregate, i.e. $\sum_{i=1}^{m} \tilde{z}_{i l}<0$, where the subscript $l$ denotes labour. Or, if $\hat{z}_{i l}$ represents Walrasian demand for labour, one can interpret the situation where $\sum_{i=1}^{m} \hat{z}_{i l}<0$ at prices $p$ as an unemployment equilibrium. Finally, one can compare aggregate allocations by the ranking $\sum_{i=1}^{m}\left|z_{i l}\right|$. If the length of the vector $\left(z_{i l}^{1}\right)_{i=1}^{m}$ in equilibrium number one is larger than the length of the vector $\left(z_{i l}^{2}\right)_{i=1}^{m}$ in equilibrium number two, then the second equilibrium must represent a lower level of economic activity than the first, and equilibrium number two can be called an unemployment equilibrium. All three of these kinds of unemployment can arise in an MCI equilibrium.

We now exhibit a class of examples in which, even at Walrasian equilibrium prices, any level of unemployment is consistent with an MCI equilibrium. These unemployment equilibria are strong in the sense that not only do offers balance each other (i.e. sum to 0) but offers equal final allocations. Thus there is no pressure on prices and no discrepancy between offers and actual trades.

The mechanism by which unemployment is sustained as an equilibrium position is like a prisoner's dilemma. If all agents made their Walrasian equilibrium offers then markets would clear with full employment. Everyone would be better off than in the MCI equilibria. Starting from an MCI equilibrium position, however, if one or a few agents make their Walrasian offers, they may make other agents better off, but their own allocations become less desirable. Thus, individually maximal policy results in an allocation that is suboptimal for the economy as a whole.

We need several additional conditions to obtain this result. The first two are on the market allocation mechanism.

Definition. We say the allocation mechanism $F$ is balance-preserving if $F(\tilde{Z})=\tilde{Z}$ whenever $\sum_{i=1}^{m} \tilde{z}_{i}=0$.

This simply says that offers equal final trades whenever offers to buy and sell balance out.

Let $\hat{p}$ be a competitive equilibrium price vector and let $\hat{z}_{i j}$, for all $i$ and $j$, be the Walrasian demand for good $j$ by household $i$ at prices $\hat{p}$. Clearly, if $F$ is balance-preserving, then $F(\hat{Z})=\hat{Z}$.

We will next suppose that labour is named in the sense that each household's labour is different from any other household's labour, i.e.

$$
\omega_{i j}= \begin{cases}0 & \text { if } j \neq i \text { and } j \leqq m_{h} \\ \omega^{i} & \text { if } j=i \\ \text { arbitrary } & \text { if } m_{h}<j \leqq n\end{cases}
$$

where $m_{h}$ is the number of households and $\omega^{i}$ is the aggregate endowment of good $i$. Commodities $j=1, \ldots, m_{h}$ are named labour. Different households' labour may be arbitrarily close (but not perfect) substitutes. The essential point is that labour of different households be treated differentially by the allocation mechanism.

The family of unemployment equilibria whose existence is asserted below takes place at Walrasian equilibrium prices. To be sure that such prices exist, we would need to assume 
indirect resource-relatedness (c.f. Arrow-Hahn (1971)), although formally the validity of the Proposition does not require the assumption. A very strong, but not unreasonable, sufficient condition for indirect resource relatedness is that every household's labour $z_{i i}$ is productive of a commodity that is desired by every other household. This property is needed only to guarantee the existence of a Walrasian equilibrium (since Assumption H.2 is contradicted below).

Proposition 1. Let $\hat{p}$ be Walrasian equilibrium prices and $(\hat{Z}, \hat{d})$ be the Walrasian trades and dividends. In addition to Assumption M.1, M.5 and M.6, and H.1, we make the following assumptions. Suppose that the allocation mechanism $F$ is balance-preserving, that labour is named, that every household's endowment consists solely of his own labour (so $\bar{M}_{i}=0$ and $\omega_{i j}=0$ for $j \neq i$ ), that $\omega_{i} \in C_{i}$ and that $\hat{z}_{i} \in K_{i}$.

For $i \in H$, let

$$
U_{i}\left(\omega_{i}+z_{i}, M_{i}\right)=u_{i}\left(\omega_{i i}+z_{i i}, \quad \theta_{i}\left(z_{i 1}, z_{i 2}, \ldots, z_{i i-1}, z_{i i+1}, \ldots, z_{i N}, M_{i}\right)\right)
$$

where $u_{i}, \theta_{i}$ are strictly concave and $\theta_{i}$ is homothetic. Household preferences thus are assumed weakly separable in the endowed good and homothetic in all other goods and money.

For $i \in F$, suppose that $Y_{i}$ exhibits constant returns, convexity, free disposal and $0 \in Y_{i}$, that in addition $\bar{M}_{i}=0, \hat{z}_{i} \in K_{i}$, the objective function can be written $U_{i}\left(-p z_{i}, M_{i}, d_{i}\right)$ and $U_{i}$ is increasing and strictly quasi-concave. Let $0 \leqq \lambda \leqq 1$; then $(\lambda \hat{z}, \lambda \hat{d})$ is a strong MCI equilibrium at $\hat{p}$.

Remarks. The conditions of the proposition are unnecessarily strong, but at least they delineate a class of examples in which the conclusion follows. It should be plausible, after reading the proof, that unemployment is generic to this model, even at Walrasian equilibrium prices. It is simply not true that unemployment arises in this model only for the reason that prices are fixed at disequilibrium levels. The exact proportionality of MCI equilibria to Walrasian excess demands seems unlikely without all of the above conditions, but that is not the central point of the proposition. In the strong equilibria of the proposition, inasmuch as $\tilde{z}_{i}=\lambda \hat{z}_{i}$, we have $\sum_{i} \tilde{z}_{i}=0$. Thus, in these unemployment equilibria there is no market force acting upon any price. This is a theory of "hidden unemployment".

Proof. We first show that $\left(\lambda \hat{z}_{i}, \lambda \hat{d}_{i}\right)$ is optimal for any firm, given the other offers $\lambda \hat{Z}_{i}$. By constant returns, $\hat{p} \hat{z}_{i}=0$ and because $\bar{M}_{i}=0$, we have $0 \leqq \hat{M}_{i} \equiv-\hat{d}_{i} \leqq 0$, so $\hat{M}_{i}=\hat{d}_{i}=0\left(\hat{M}_{i}\right.$ is Walrasian money demand). Thus, $-\hat{p} \hat{z}_{i}=-\hat{p}\left(\lambda \hat{z}_{i}\right), \hat{M}_{i}=\lambda \hat{M}_{i}$ and $\hat{d}_{i}=\lambda \hat{d}_{i}$ so the firm is just as well off (given our condition that $U_{i}$ is a function just of $-p z_{i}, M_{i}$ and $\left.d_{i}\right)$ under $(\lambda \hat{Z}, \lambda \hat{d})$ as it was under the Walrasian equilibrium. Indeed, because it takes prices parametrically, the firm cannot make a positive profit under $\hat{p}$, so $\left(\lambda \hat{z}_{i}, \lambda \hat{d}_{i}\right)$ is optimal for the firm, as claimed.

The household decision is more difficult. The budget constraint is satisfied at $\lambda \hat{z}_{i}$, because $\bar{M}_{i}=0$ (for all $i$ ) and $\hat{d}_{i}=0$ (for $i \in F$ ), so that $\hat{p} \hat{z}_{i}=0$ for $i \in H$ and hence $\hat{p}\left(\lambda \hat{z}_{i}\right)=0$. On the other hand, $F_{i}(\lambda \hat{Z})=\lambda \hat{z}_{i}$ by the balance-preserving property of the allocation mechanism, and $\lambda \hat{z}_{i} \in K_{i}$ (since 0 and $\hat{z}_{i}$ belong to $K_{i}$ and $K_{i}$ is convex). The convexity of $C_{i}$ also implies that $\omega_{i}+\lambda \hat{z}_{i} \in C_{i}$. Thus $\lambda \hat{z}_{i}$ is possible for the household.

To show that $\lambda \hat{z}_{i}$ is optimal takes more work. First, we show that $\lambda \hat{z}_{i i}$ is (in absolute value) the most the household can supply of its labour. For, given $\lambda \hat{Z}_{i}$ as other agents' offers, and for any $\tilde{z}_{i i}$ such that $\tilde{z}_{i i} \geqq \lambda \hat{z}_{i i}$, the demand by agent $k$ for household $i$ 's labour is $F_{k i}\left(\tilde{z}_{i}, \lambda \hat{Z}_{i}\right)=\lambda \hat{z}_{k i}$ for agents $k \neq i$ (since $F$ is one-sided and $\left.\tilde{z}_{i i} \geqq \lambda \hat{z}_{i i}=-\lambda \sum_{k \neq i} \hat{z}_{k i}\right)$. From the fact that agent $i$ is the only supplier of the $i$ th commodity, it follows that any increase in $i$ 's offer to supply that commodity will not increase $i$ 's actual sales of commodity $i$. Given that it cannot increase its actual hours worked to the Walrasian level, would it be better for the household to decrease its actual labour time below $\lambda \hat{z}_{i i}$ ? That the answer is "no" follows immediately from the weak separability of $U_{i}$ and concavity of $u_{i}, \theta_{i}$. 
By homotheticity of $\theta_{i}, \lambda \hat{z}_{i j}, j \neq i$, is the optimizing bundle for $\theta_{i}$ subject to the budget constraint $\bar{M}_{i}-p \cdot z_{i} \geqq 0, z_{i i}=\lambda \hat{z}_{i i}, \bar{M}_{i}=0, z_{i}+\omega_{i} \geqq 0, \omega_{i j}=0, j \neq i$. This completes the proof.

We now present a class of examples of unemployment equilibria with money holding. The unemployment in these examples is due to either a deficient money supply, or, what is the same thing, a nominal price level for goods that is too high.

Proposition 2. Let the economy be as in Proposition 1, except that household preferences are now additively separable:

$$
U_{i}\left(\omega_{i}+z_{i}, M_{i}\right)=u_{i}\left(\omega_{i i}+z_{i i}\right)+\theta_{i}\left(z_{i 1}, \ldots, z_{i i-1}, z_{i i+1}, \ldots, z_{i n}, M_{i}\right)
$$

Let $\hat{p}, \hat{Z}$ be a Walrasian equilibrium for this economy when $\bar{M}_{i}>0, i \in H$ and $\bar{M}_{i}=0, i \in F$. Let $\hat{M}_{i}$ be $i$ 's Walrasian equilibrium money holding. Consider now an identical economy with money endowments $\lambda \bar{M}_{i}, 0<\lambda \leqq 1$. Then the conclusions of Proposition 1 still hold, that is, $(\lambda \hat{\mathrm{Z}}, \lambda \hat{d})$ is a strong MCI equilibrium at $\hat{p}$. Further, $(\lambda \hat{\mathrm{Z}}, \lambda \hat{d})$ is not a Walrasian equilibrium.

Proof. The behaviour of firms and of households with respect to $\tilde{z}_{i i}$ is identical to that of Proposition 1. Recall that $\hat{d}_{i}=0$ for all firms $i \in F$. We have to establish that $\lambda \hat{z}_{i j}, j \neq i$ and $M_{i}^{0}=\lambda \bar{M}_{i}-\lambda \hat{p} \cdot \hat{z}_{i}$ maximizes $\theta_{i}(z, M)$ subject to $M_{i}=\lambda \bar{M}_{i}-\hat{p} \cdot z \geqq 0$, $z_{i i}=\lambda \hat{z}_{i i}$. But $M_{i}^{0}=\lambda \hat{M}_{i}$, so (by homotheticity of $\theta_{i}$ ) $M_{i}^{0}, \lambda \hat{z}_{i j}, j \neq i$ is maximal. The prices $\hat{p}$ are not Walrasian equilibrium prices for the economy with endowments $\left(\omega_{i}, \lambda \bar{M}_{i}\right)$; nominal prices are too high for the (reduced) money stock. To confirm that markets do not clear in the Walrasian sense, simply note that the typical household $i$ has an excess supply of the endowed good, $i$. This follows directly from the separability of $U_{i}$ in $M$ and $z_{i i}$ and strict concavity of $u_{i}$ and $\theta_{i}$. Consider the marginal rates of substitution between money and the endowed good. We will argue that:

$$
\operatorname{MRS}_{M, z_{i i}}=\frac{\frac{\partial \theta_{i}\left(\lambda \hat{z}_{i}, \lambda \bar{M}_{i}\right)}{\partial M}}{u_{i}^{\prime}\left(\omega_{i i}+\lambda \hat{z}_{i i}\right)}>\frac{\frac{\partial \theta_{i}\left(\hat{z}_{i}, \bar{M}_{i}\right)}{\partial M}}{u_{i}^{\prime}\left(\omega_{i i}+\hat{z}_{i i}\right)}=\frac{\hat{p}_{M}}{\hat{p}_{i}}=\frac{1}{\hat{p}_{i}}
$$

The LHS of the inequality is the MRS of money for the endowed commodity at the MCI equilibrium. The RHS is the MRS that would obtain at the household maximum utility subject to budget constraint (Walrasian allocation). The inequality then follows from the strict concavity of $\theta_{i}$ and $u_{i}$. Thus the strong MCI equilibrium of Proposition 2 is not a Walrasian equilibrium.

With the introduction of an additional condition we can use the results of Propositions 1 and 2 to construct a family of MCI equilibria with active excess supplies, that is $\tilde{z}_{i} \neq z_{i}, \sum_{i} \tilde{z}_{i} \leqq 0$. By definition these equilibria will not be "strong". Note that in the strong equilibria of the Propositions, the typical trader should be indifferent among offers $\tilde{z}_{i i}$ to supply any amount between the volume of sales the market will absorb $\lambda \hat{z}_{i i}$ and a larger (in absolute value) supply. The amount actually sold will remain $\lambda \hat{z}_{i i}$. This will be so if making an offer greater than $\lambda \hat{z}_{i i}$ on the market for good $i$, (offers for other goods $j \neq i$ held constant at $\lambda \hat{z}_{i j}$ ) has no effect through $F$ on the allocation of goods other than $i$. If this independence condition on $F$ holds, then, under the assumptions of the Propositions, the offers $\tilde{z}_{i}$ with $\tilde{z}_{i j}=\lambda \hat{z}_{i j}(j \neq 1)$ and $\tilde{z}_{i i} \leqq \lambda \hat{z}_{i i}<0$, and dividends $\lambda \hat{d}$ constitute MCI equilibria at $\hat{p}$. These equilibria have the property that markets can be seen directly not to clear since $\sum_{i} \tilde{z}_{i j}$ may be less than 0 (active excess supply).

\section{RELATIONSHIP TO THE LITERATURE}

Walrasian household behaviour consists of optimizing subject to a budget constraint ignoring any quantity constraint on purchases and possible disparity between an offer to 
the market and realized transactions. The household acts-even at the disequilibrium prices-as though it expects markets to clear. A first approach to unemployment equilibrium is to consider a market with no excess demand and excess supply for one good only (e.g. labour). Clower (1965) and Glustoff (1968) suggest that sellers of such a good in excess supply optimize subject to a well-defined quantity constraint on sales. This implies, through the budget constraint, that demands for other goods are reduced from their Walrasian levels.

Several models (Drèze (1975), Grandmont-Laroque (1976), Hahn (1978)) suggest that the household perceives well-defined quantity constraints on several markets simultaneously. It makes no offer in excess of those constraints. Household $i$ chooses $z_{i}$ to

$$
\max U_{i}\left(\omega_{i}+z_{i}, M_{i}\right)
$$

subject to

(a) $\underline{\zeta}_{i} \leqq z_{i} \leqq \bar{\zeta}_{i}$, component-wise (the $\zeta$ 's are upper and lower quantity constraint vectors)

(b) $p z_{i}+M_{i} \leqq \bar{M}_{i}$

(c) $M_{i} \geqq 0$

(d) $\omega_{i}+z_{i} \geqq 0$.

Note that in this model there is no distinction between offers and realized transactions. Equilibrium then consists of a set of rationed allotments $\underline{\zeta}_{i}, \bar{\zeta}_{i}$ so that market actions clear, that is, so that $\sum_{i} z_{i}=0$.

Existence of equilibrium is achieved under relatively weak continuity and convexity conditions. An apparently fundamental problem is that in equilibrium there is no explicit concept of excess demand and supply $\left(z_{i} \equiv \tilde{z}_{i}\right)$. Grandmont contends, however, that there is a formal equivalence of this approach to that of Benassy below that allows one to interpret it to include well-defined excess demands.

Another view of how market disequilibrium enters the constraint set faced by individual actors is put forth by Benassy (1975). As in our model, Benassy (1975) explicitly accounts for the fact that there are non-price interdependencies under rationing. Arrow (1959) was the first to point out that in disequilibrium actions by any one agent affect the market opportunities of other agents, and that agents will take this into account when formulating their actions. Unlike our model, Benassy assumes that economic agents formulate expectations, probably incorrect but not grossly inaccurate, of purchase and sale opportunities open to them. In equilibrium the expectations are correct and self-reproducing. The agents formulate their offers sequentially among markets, constrained on one market by the expected degree of fulfilment of offers to other markets. Thus, an agent's offer to buy right shoes will depend on the expected degree of fulfilment of his offer for left shoes. This ignores two possibilities: it may be (expected) utility maximizing to offer to buy more than the expected constraint of both kinds of shoes, though not for either sort separately; it is possible that one commodity's actual allocation be influenced by orders on another market (in the USSR, you may have to buy bad apples along with oranges). To clarify the discussion of the Benassy model let us introduce the following additional notation:

$\underline{G}_{i j}(\tilde{Z}), \bar{G}_{i j}(\tilde{Z}): i$ 's rationing expectation functions for $\operatorname{good} j$, assumed to reflect correctly the degree of excess demand and supply.

Consider household $i$ 's offer to the market for good $k$. For each commodity $k=1, \ldots, n$ choose $\tilde{z}_{i}(k) \in R^{n}$. In deciding how much to offer to buy or sell of commodity $k$, the quantity constraints on $k$ are not taken to be binding. That is

$$
\tilde{z}_{i}(k) \max U_{i}\left(\omega_{i}+\tilde{z}_{i}(k), M_{i}(k)\right)
$$


subject to

(e) $\underline{G}_{i j}\left(\tilde{Z}_{i}\right) \leqq \tilde{z}_{i j}(k) \leqq \bar{G}_{i j}\left(\tilde{Z}_{i}\right), j \neq k$

(f) $p \tilde{z}_{i}(k)+M_{i}(k) \leqq M_{i}$

(g) $M_{i}(k) \geqq 0$

(h) $\omega_{i}+\tilde{z}_{i}(k) \geqq 0$

(i) $\tilde{z}_{i}(k) \in K_{i}$.

Household $i$ 's actual offer is the diagonal of the array of $\tilde{z}_{i j}(k)$.

$$
\tilde{z}_{i}=\left(\tilde{z}_{i 1}(1), \tilde{z}_{i 2}(2), \ldots, \tilde{z}_{i j}(j), \ldots, \tilde{z}_{i n}(n)\right) \text {. }
$$

On the market for each commodity the traders express an offer which may violate the quantity constraints they expect for that good. It represents their most preferred allocation of the good (unconstrained) assuming quantity constraints to hold on all other markets. The offer for each commodity is based on an optimization subject to constraints which vary with the good in question. The offer for each good, considered separately, is rationally based and fulfils constraints. The constraints are, however, continually changing. Hence no optimality or affordability properties can be ascribed to the complex of offers, $\tilde{z}_{i}$, made by household $i$ for all goods taken together.

Equilibrium (known as K-equilibrium) then is a constellation of offers $\tilde{Z}^{*}$ so that subject to (e)-(i) and $G_{i}\left(\tilde{Z}^{*}\right)$, no household $i$ has an incentive to revise $\tilde{z}_{i}^{*}$. Existence of equilibrium requires continuity of $G$. This approach treats the $n$-market disequilibrium problem as $n$ related, but separable, partial disequilibrium problems. Its strength is that it achieves a plausible and explicit concept of excess supply and demand. It is rational mainly in the sense that in equilibrium expectations are fulfilled. Defects are that $\tilde{z}_{i}$ does not in fact represent an optimizing combination of demands and supplies (indeed, it may not even be affordable), and that the possibility of interactions in the allocation mechanism among distinct commodity markets is ignored in individual decision making.

Our approach differs from that of Benassy in several respects. Expectations about quantities that can actually be transacted (Benassy's formulation) are replaced here by accurate individual perceptions about quantities that may be traded. We use a more general allocation mechanism than was possible in Benassy. In addition, a sequential decision process in which each commodity is considered separately is replaced by a simultaneous decision process in which (like the Walrasian model) offers to all markets are considered at once.

Benassy (1975) and Grandmont-Laroque (1976) have extended their models to include price-setting behaviour by monopolistic competitors. The difficulty with these models is that excess supply equilibrium may come about solely from the fact that firms and workers set their price monopolistically in the current period, but take all prices as given next period. Hence, in the next period, firms wish to supply more (in their incarnation as perfect competitors) than other agents wish to buy at the monopoly price.

The above approaches assume rigidly fixed quantity constraints as perceived by the household. These perceptions are generally incorrect except in equilibrium. By contrast, in myopic complete information models the household has a correct perception of the allocation resulting from its offer (when other offers are presumed constant) both in and out of equilibrium. ${ }^{6}$ Further, in contrast to the Benassy model, the household's offer is genuinely optimizing.

\section{PROOFS}

Lemma 1. For $i=1,2, \ldots, m$ the correspondence $S_{i}$ has a non-empty closed graph, under Assumptions M.1, M.2, H.1 and F.2. 
Proof. Closedness follows readily from the closedness of $C_{i}$ and $Y_{i}$ and the continuity of $F_{i}$, linear functions and inequalities; non-emptiness follows from the fact that the no trade offer is always possible.

Lemma 2. Under Assumptions M.1, M.2, M.4, H.2 and F.2, the correspondences int $S_{i}\left(\widetilde{Z}_{i}, d\right)($ for $i \in H)$ and int $S_{i}\left(\widetilde{Z}_{i}\right)($ for $i \in F)$ are all non-empty and lower hemi-continuous.

Proof. First note that $0 \in \operatorname{int} S_{i}\left(\tilde{Z}_{i}, d\right)$ if $i \in H$. For, $F_{i}\left(0, \tilde{Z}_{i}\right)=0 \in \operatorname{int} B_{i}(d)$, by Assumptions M.2 and H.2. But, by Assumption M.1, $0 \in \operatorname{int} K_{i}$. By continuity of $F_{i}$, there exists a neighbourhood of $0, N(0)$, such that $N(0) \subset K_{i}$ and $\tilde{z}_{i} \in N(0)$ implies $F_{i}\left(\tilde{z}_{i}, \tilde{Z}_{i}\right) \in$ int $B_{i}(d)$. Thus, $N(0) \subset S_{i}\left(\tilde{Z}_{i}, d\right)$.

We now demonstrate that $S_{i}\left(Z_{i}\right)$ for $i \in F$ contains a non-empty open set (and therefore has a non-empty interior). It is true that there exists $\hat{d}_{i}>0$, such that $\left(0, \hat{d}_{i}\right) \in \operatorname{int} S_{i}\left(\widetilde{Z}_{i}\right)$, if $i \in F$. For, if $\hat{d}_{i}>0$ is sufficiently small, $F_{i}\left(0, \widetilde{Z}_{i}\right)=0 \in \operatorname{int} B_{i}\left(\hat{d}_{i}\right)$, by Assumptions M.2 and F.2, since $0 \in \operatorname{int} Y_{i}$ and $\bar{M}_{i}-\hat{d}_{i}>0$. By Assumption M.1, $0 \in$ int $K_{i}$. By continuity again, there exists $N(0) \subset K_{i}$ such that $\tilde{z}_{i} \in N(0)$ implies $F_{i}\left(\tilde{z}_{i}, \tilde{Z}_{i}\right) \in \operatorname{int} B_{i}\left(\hat{d}_{i}\right)$. But $B_{i}\left(\hat{d}_{i}\right)$ is lower hemi-continuous and convex valued, so there also exists a neighbourhood $M\left(\partial_{i}\right)$ sufficiently small such that $\left(\tilde{z}_{i}, d_{i}\right) \in N(0) \times M\left(\hat{d}_{i}\right)$ implies $F_{i}\left(\tilde{z}_{i}, \tilde{Z}_{i}\right) \in \operatorname{int} B_{i}\left(d_{i}\right)$. Thus $N(0) \times M\left(\hat{d}_{i}\right) \subset S_{i}\left(\widetilde{Z}_{i}\right)$.

We now prove lower hemi-continuity (abbreviated 1.h.c.) for $i \in H$. Let $G$ be any open set such that int $S_{i}\left(\tilde{Z}_{i}^{0}, d^{0}\right) \cap G \neq \varnothing$. (We must show that there exists a neighbourhood $N\left(\widetilde{Z}_{i}^{0}, d^{0}\right)$ such that $\left(\widetilde{Z}_{i}, d\right) \in N\left(\widetilde{Z}_{i}^{0}, d^{0}\right)$ implies int $S_{i}\left(\widetilde{Z}_{i}, d\right) \cap G \neq \varnothing$.) By assumption, there exists $\tilde{z}_{i}^{0} \in \operatorname{int} K_{i} \cap G$ such that $z_{i}^{0}=F_{i}\left(\tilde{z}_{i}^{0}, \widetilde{Z}_{i}^{0}\right) \in B_{i}\left(d^{0}\right)$. We first show that there exists $\hat{z}_{i} \in \operatorname{int} K_{i} \cap G$ such that $F_{i}\left(\hat{\mathrm{z}}_{i}, \tilde{Z}_{i}^{0}\right) \in \operatorname{int} B_{i}\left(d^{0}\right)$. But $0 \in \operatorname{int} B_{i}\left(d^{0}\right)$, so for $0<\lambda<1$

$$
(1-\lambda) z_{i}^{0}+\lambda 0 \in \operatorname{int} B_{i}\left(d^{0}\right) \text {, }
$$

since $B_{i}\left(d^{0}\right)$ is convex. On the other hand, $0=F_{i}\left(0, \widetilde{Z}_{i}^{0}\right)$, thus by Assumption M.4, for every neighbourhood $N\left(\tilde{z}_{i}^{0}\right)$, there exists $\hat{z}_{i} \in N\left(\tilde{z}_{i}^{0}\right)$ such that $F_{i}\left(\hat{z}_{i}, \widetilde{z}_{i}^{0}\right)=(1-\lambda) z_{i}^{0}+\lambda 0$, for some $\lambda, 0<\lambda<1$. Let $N\left(\tilde{z}_{i}^{0}\right)$ be chosen so that $N\left(\tilde{z}_{i}^{0}\right) \subset G \cap i n t K_{i}$. Putting all this together, we have just shown that there exists $\hat{z}_{i} \in G \cap \operatorname{int} K_{i}$ such that $F_{i}\left(\hat{z}_{i}, \tilde{Z}_{i}^{0}\right) \in \operatorname{int} B_{i}\left(d^{0}\right)$.

The next stage of the proof consists of showing that there is a neighbourhood of $\left(\widetilde{Z}_{i}^{0}, d^{0}\right), N\left(\widetilde{Z}_{i}^{0}, d^{0}\right)$, such that $\left(\tilde{Z}_{i}, d\right) \in N\left(\widetilde{Z}_{i}^{0}, d^{0}\right)$ implies $F_{i}\left(\hat{z}_{i}, \widetilde{Z}_{i}\right) \in B_{i}(d)$. By the usual arguments of Debreu (1959), $B_{i}(d)$ is a continuous, convex-valued correspondence. By Proposition 3.3 of Heller (1978), $F_{i}\left(\hat{z}_{i}, \tilde{Z}_{i}^{0}\right) \in \operatorname{int} B_{i}(d)$ for $d$ in some closed neighbourhood $N_{1}\left(d^{0}\right)$. Let $\underline{d}=\min \left\{\sum_{f} \alpha_{i f} d_{f} \mid d \in N_{1}\left(d^{0}\right)\right\}$ be the smallest dividend total for household $i$ in $N_{1}\left(d^{0}\right)$. By the definition of $B_{i}(d), B_{i}\left(d^{1}\right) \subset B_{i}(d)$ for $d \in N_{1}\left(d^{0}\right)$, where $d^{1}$ is a vector $\left(d_{f}\right)$ in $N_{1}\left(d^{0}\right)$ corresponding to the number $\underline{d}$. Because $d^{1} \in N_{1}\left(d^{0}\right), F_{i}\left(\hat{\mathrm{z}}_{i}, \widetilde{Z}_{i}^{0}\right) \in \operatorname{int} B_{i}\left(d^{1}\right)$. But int $B_{1}\left(d^{1}\right)$ is an open set, so by continuity of $F_{i}$, there exists a neighbourhood of $\widetilde{Z}_{i}^{0}, \quad N_{2}\left(\widetilde{Z}_{i}^{0}\right)$, such that $\widetilde{Z}_{i} \in N_{2}\left(\widetilde{Z}_{i}^{0}\right)$ implies $F_{i}\left(\hat{Z}_{i}, \tilde{Z}_{i}\right) \in \operatorname{int} B_{i}\left(d^{1}\right)$. Therefore, if $\left(\widetilde{Z}_{i}, d\right) \in N_{2}\left(\widetilde{Z}_{i}^{0}\right) \times N_{1}\left(d^{0}\right)$ then $F_{i}\left(\hat{z}_{i}, \widetilde{Z}_{i}\right) \in$ int $B_{i}\left(d^{1}\right) \subset \operatorname{int} B_{i}(d)$, as was to be shown.

Since $\hat{z}_{i} \in$ int $K_{i} \cap G$, we know that $\hat{z}_{i} \in$ int $S_{i}\left(\widetilde{Z}_{i}, d\right) \cap G$ for $\left(\widetilde{Z}_{i}, d\right) \in N_{2}\left(\widetilde{Z}_{i}^{0}\right) \times N_{1}\left(d^{0}\right)$, so int $S_{i}\left(\widetilde{Z}_{i}, d\right)$ is 1. h.c. for $i \in H$.

Now suppose $i \in F$ and int $S_{i}\left(\tilde{Z}_{i}^{0}\right) \cap E \neq \varnothing$ for any open set $E$. Then there exists $\tilde{z}_{i}^{0} \in$ int $K_{i}$ and $d_{i}^{0}>0$ such that $F_{i}\left(\tilde{z}_{i}^{0}, \widetilde{Z}_{i}^{0}\right) \in B_{i}\left(d_{i}^{0}\right)$ and $\left(\tilde{z}_{i}^{0}, d_{i}^{0}\right) \in E$. For 1.h.c., it suffices to show that for some neighbourhood, $N\left(\widetilde{Z}_{i}^{0}\right), \widetilde{Z}_{i} \in N\left(\widetilde{Z}_{i}^{0}\right)$ implies there exists $z_{i} \in \operatorname{int} K_{i}$ and $\hat{d}_{i}>0$ such that $F_{i}\left(\hat{z}_{i}, \widetilde{Z}_{i}\right) \in$ int $B_{i}\left(\hat{d}_{i}\right)$ and $\left(\hat{z}_{i}, \hat{d}_{i}\right) \in E$. By Assumption M.4 and the corresponding argument for the case $i \in H$, for every neighbourhood $M_{1}\left(\tilde{z}_{i}^{0}\right)$, there exists $\hat{z}_{i} \in M_{1}\left(\tilde{z}_{i}^{0}\right)$ such that $F_{i}\left(\hat{z}_{i}, \tilde{Z}_{i}^{0}\right) \in \operatorname{int} B_{i}\left(d_{i}^{0}\right)$. Again, by the corresponding argument for $i \in H$, there exists a neighbourhood of $d_{i}^{0}, M_{2}\left(d_{i}^{0}\right)$, such that $F_{i}\left(\hat{z}_{i}, \widetilde{Z}_{i}^{0}\right) \in \operatorname{int} B_{i}\left(d_{i}\right)$ for $d_{i} \in M_{2}\left(d^{0}\right)$. Indeed, let $M_{2}\left(d_{i}^{0}\right)$ be chosen so that

$$
0<\inf \left\{d_{i} \mid d_{i} \in M_{2}\left(d_{i}^{0}\right)\right\}<d_{i}^{0}<\sup \left\{d_{i} \mid d_{i} \in M_{2}\left(d_{i}^{0}\right)\right\}<\bar{M}_{i}-p F_{i}\left(\hat{z}_{i}, \widetilde{Z}_{i}^{0}\right) .
$$


Then, defining $d_{i}^{1}=\sup \left\{d_{i} \mid d_{i} \in M_{2}\left(d_{i}^{0}\right)\right\}$, int $B_{i}\left(d_{i}^{1}\right) \subset \operatorname{int} B_{i}\left(d_{i}\right)$ for all $d_{i} \in M_{2}\left(d_{i}^{0}\right)$. Thus, by continuity of $F_{i}$ and the corresponding argument for $i \in H$, there exists a neighbourhood, $N\left(\widetilde{Z}_{i}^{0}\right)$, of $\widetilde{Z}_{i}^{0}$ such that $F_{i}\left(\hat{z}_{i}, \widetilde{Z}_{i}\right) \in \operatorname{int} B_{i}\left(d_{i}\right)$ for all $\widetilde{Z}_{i} \in N\left(\widetilde{Z}_{i}^{0}\right)$ and $d_{i} \in M_{2}\left(d_{i}^{0}\right)$. Let $M_{1}\left(\tilde{z}_{i}^{0}\right)$ and $M_{2}\left(d_{i}^{0}\right)$ be chosen sufficiently small so that

$$
M_{1}\left(\tilde{z}_{i}^{0}\right) \times M_{2}\left(d_{i}^{0}\right) \subset\left\{\operatorname{int} K_{i} \times G\left(F_{i}\left(\tilde{z}_{i}^{0}, \tilde{Z}_{i}^{0}\right)\right)\right\} \cap E,
$$

$$
\text { where } G\left(F_{i}\left(\tilde{z}_{i}^{0}, \tilde{Z}_{i}^{0}\right)\right)=\left\{d_{i} \mid \bar{M}_{i}-p F_{i}\left(\tilde{z}_{i}^{0}, \tilde{Z}_{i}^{0}\right) \geqq d_{i} \geqq 0\right\} \text {. }
$$

Thus, there exists $\left(\hat{z}_{i}, \hat{d}_{i}\right) \in E$ such that $\hat{z}_{i} \in \operatorname{int} K_{i}, \hat{d}_{i}>0$ and $F_{i}\left(\hat{z}_{i}, \widetilde{Z}_{i}\right) \in$ int $B_{i}\left(\hat{d}_{i}\right)$ for all $\widetilde{Z}_{i} \in N\left(\widetilde{Z}_{i}^{0}\right)$.

Lemma 3. Under the same assumptions as Lemma $2, S_{i}\left(\widetilde{Z}_{i}, d\right)$ for $i \in H$ and $S_{i}\left(\widetilde{Z}_{i}\right)$ for $i \in F$ are continuous correspondences with non-empty compact values.

Proof. We have shown non-emptiness; that the $S_{i}$ have closed values follows from continuity and closedness of all relevant sets; upper hemi-continuity and boundedness of the values of the $S_{i}$ follows from Lemma 1 and the fact that the values of the correspondences all lie in a compact set.

We have shown the lower hemi-continuity of the int $S_{i}\left(\tilde{Z}_{i}, d\right) \quad(i \in H)$ and int $S_{i}\left(\tilde{Z}_{i}\right) \quad(i \in F)$. It is well known that the closure of a lower hemi-continuous correspondence is also lower hemi-continuous. But then by the non-emptiness, closedness and convexity of $S_{i}\left(\widetilde{Z}_{i}, d\right)$ (Assumptions M.1 and M.3),

$$
\overline{\text { int } S_{i}\left(\tilde{Z}_{i}, d\right)}=S_{i}\left(\tilde{Z}_{i}, d\right)
$$

is also lower hemi-continuous. $\|$

Lemma 4. $V_{i}\left(\tilde{z}_{i}, \tilde{Z}_{i}, d\right)$ for $i \in H$ and $V_{i}\left(\tilde{z}_{i}, d_{i}, \tilde{Z}_{i}\right)$ for $i \in F$ are continuous functions under Assumptions M.2, H.1 and F.1.

Proof. Follows directly from continuity of $U_{i}$ and $F_{i}$. $\|$

Lemma 5. Let $K=X_{i=1}^{m} K_{i}$. Under the above assumptions,

$$
\phi_{i}\left(\tilde{Z}_{i}, d\right)=\max \left\{V_{i}\left(\tilde{z}_{i}, \tilde{Z}_{i}, d\right) \mid \tilde{z}_{i} \in S_{i}\left(\tilde{Z}_{i}, d\right)\right\} \text { for } i \in H
$$

and

$$
\phi_{i}\left(\tilde{Z}_{i}\right)=\max \left\{V_{i}\left(\tilde{z}_{i}, d_{i}, \tilde{Z}_{i}\right) \mid\left(\tilde{z}_{i}, d_{i}\right) \in S_{i}\left(\tilde{Z}_{i}\right)\right\} \text { for } i \in F
$$

are continuous functions on $K \times R_{+}$. Also,

and

$$
\gamma_{i}\left(\tilde{Z}_{i}, d\right)=\left\{\tilde{z}_{i} \in S_{i}\left(\tilde{Z}_{i}, d\right) \mid V_{i}\left(\tilde{z}_{i}, \tilde{Z}_{i}, d\right)=\phi_{i}\left(\tilde{Z}_{i}, d\right)\right\} \text { for } i \in H
$$

$$
\gamma_{i}\left(\tilde{Z}_{i}\right)=\left\{\left(\tilde{z}_{i}, d_{i}\right) \in S_{i}\left(\tilde{Z}_{i}\right) \mid V_{i}\left(\tilde{z}_{i}, d_{i}, \tilde{Z}_{i}\right)=\phi_{i}\left(\tilde{Z}_{i}\right)\right\} \text { for } i \in F
$$

are upper hemi-continuous correspondences.

Proof. Follows directly from Lemmas 3 and 4 and the Maximum Theorem (see for example Berge (1963)).

Lemma 6. For $i \in H, \gamma_{i}\left(\widetilde{Z}_{i}, d\right)$ and for $i \in F, \gamma_{i}\left(\widetilde{Z}_{i}\right)$ (i.e. the maximizing offer sets) are convex sets for all possible $\widetilde{Z}_{i}, d$, under the above assumptions. Further, maximizing trade sets are singletons (i.e. $\left.\left.F_{i}\left(\gamma_{i}\left(\widetilde{Z}_{i}, d\right), \widetilde{Z}_{i}\right)=z_{i}^{*}\right\}\right)$, as are the maximizing dividend offers $d^{*}$.

Proof. For $i \in H$ denote the upper contour set at the maximum by

$$
\Gamma_{i}\left(\tilde{Z}_{i}, d\right)=\left\{z_{i} \mid U_{i}\left(z_{i}+\omega_{i}, \bar{M}_{i}+\sum \alpha_{i f} d_{f}-p z_{i}\right) \geqq \phi_{i}\left(\tilde{Z}_{i}, d\right)\right\} .
$$

By Assumption H.1, $\Gamma_{i}\left(\tilde{Z}_{i}, d\right)$ is strictly convex. The $z_{i}$ are chosen from $F_{i}\left(K_{i}, Z_{i}\right) \cap B_{i}(d)$, a convex set by Assumption M.3. Hence, by the usual argument, there is a unique 
maximizer $z_{i}^{*}$. But then $\gamma_{i}\left(\widetilde{Z}_{i}, d\right)=F_{i}^{-1}\left(z_{i}^{*}, \widetilde{Z}_{i}\right)$ which is convex, again by Assumption M.3.

For $i \in F$, let $\Gamma_{i}\left(\widetilde{Z}_{i}\right)=\left\{\left(z_{i}, d_{i}\right) \mid U_{i}\left(-z_{i}, M_{i}-p z_{i}-d_{i}, d_{i}\right) \geqq \phi_{i}\left(\tilde{Z}_{i}\right)\right\}$. Let

$$
A_{i} \equiv\left\{\left(z_{i}, d_{i}\right) \mid z_{i} \in Y_{i} \cap F_{i}\left(K_{i}, \tilde{Z}_{i}\right) \text { and } \bar{M}_{i}-p z_{i}-d_{i} \geqq 0\right\} \text {. }
$$

Clearly $A_{i}$ is convex by the convexity of $Y_{i}$ and $F_{i}\left(K_{i}, \tilde{Z}_{i}\right)$, while $\Gamma_{i}\left(\tilde{Z}_{i}\right)$ is strictly convex. By the usual argument, $\Gamma_{i}\left(\widetilde{Z}_{i}\right) \cap A_{i}$ is a singleton, $\left(z_{i}^{*}, d_{i}^{*}\right)$. Thus, $F_{i}^{-1}\left(z_{i}^{*}, \widetilde{Z}_{i}\right)$ is convex, by Assumption M.3 again, and so $\gamma_{i}\left(\widetilde{Z}_{i}\right)=F_{i}^{-1}\left(z_{i}^{*}, \widetilde{Z}_{i}\right) \times\left\{d_{i}^{*}\right\}$ is convex.

Lemma 7. Let $K_{i_{1}}^{\varepsilon_{1}}=\left\{\tilde{z}_{i} \in K_{i_{1}} \mid \tilde{z}_{i_{1} j} \leqq-\varepsilon_{1}\right\}$ and $K_{i_{2}}^{\varepsilon_{2}}=\left\{\tilde{z}_{i_{2}} \in K_{i_{2}} \mid \tilde{z}_{i_{2} j} \geqq \varepsilon_{2}\right\}$ for numbers $\varepsilon_{1}, \varepsilon_{2}>0$. Then $K_{i_{1}}^{\varepsilon_{1}}$ and $K_{i_{2}}^{\varepsilon_{2}}$ are compact convex sets that do not contain the zero vector.

Proof. Obvious. \|

Lemma 8. Let $K^{\varepsilon_{1}, \varepsilon_{2}}=K_{1} \times \ldots \times K_{i_{1}}^{\varepsilon_{1}} \times \ldots \times K_{i_{2}}^{\varepsilon_{2}} \times \ldots \times K_{m}$. Then the functions $\phi_{i}$ are continuous functions on $K^{\varepsilon_{1}, \varepsilon_{2}} \times R_{+}^{F}$.

Proof. The restriction of a continuous function to a smaller domain is still a continuous function.

Theorem 1. Under Assumptions M.1-M.6, H.1, H.2, F.1, F.2 and T.1, there is a nontrivial MCI equilibrium.

Proof. There exists an MCI equilibrium $\left(\widetilde{Z}^{*}, d^{*}\right)$ in the fictitious economy because all the conditions of the theorem of Debreu (1952; see the appendix of this paper) are satisfied by Lemmata $1-8$.

We now show that $\left(\widetilde{Z}^{*}, d^{*}\right)$ is an equilibrium in the original economy. Consider agent $i$ for $i \neq i_{1}$ and $i \neq i_{2}$. At $\left(\widetilde{Z}_{i}^{*}, d^{*}\right.$ ) (if $i \in H$ ), the household's opportunity set $S_{i}\left(\tilde{Z}_{i}^{*}, d^{*}\right)$ is the same. Hence, his maximizing offer is the same as before also, viz. $z_{i}^{*}$. If $i \neq i_{1}, i \neq i_{2}$ and $i \in F$, then $S_{i}\left(\widetilde{Z}_{i}^{*}\right)$ is again the same, so again $\tilde{z}_{i}^{*}$ is chosen. By Desirability of Trade, the expansion in agent $i_{1}$ 's opportunity set resulting from the dropping of the $\varepsilon_{1}$ constraint allows $i_{1}$ no action that leads to a preferred consequence (so long as $\left(\widetilde{Z}_{i}, d\right)$ is at $\left.\left(\widetilde{Z}_{i}^{*}, d^{*}\right)\right)$, since $\tilde{z}_{i_{2}}^{*} \geqq \varepsilon_{2}$. The symmetric argument works for agent $i_{2}$. Thus no agent has an incentive to move from $\left(\widetilde{Z}^{*}, d^{*}\right)$, and so $\left(\widetilde{Z}^{*}, d^{*}\right)$ is an MCI equilibrium. Note that by construction $\tilde{z}_{i_{1} j}^{*}<0$, while $\tilde{z}_{i_{2 j}}^{*}>0$, so that by Assumption M.6, $F_{i j}\left(\widetilde{Z}^{*}\right) \neq 0$ for $i=i_{1}$ and $i=i_{2}$. There is non-zero trade, and hence $\left(\widetilde{Z}^{*}, d^{*}\right)$ is a nontrivial MCI equilibrium.

Theorem 2. If, in addition to the assumptions of Theorem 1, we assume H.3, F.3 and T.2, then there is a non-trivial strong equilibrium.

Proof. We seek the fixed point of a transformation mapping offers into net trades which takes account of individual optimizations. For $i \in F$, partition $\gamma_{i}\left(\widetilde{Z}_{i}\right)$ into two components $\gamma_{i}^{0}\left(\widetilde{Z}_{i}\right)$ and $\gamma_{i}^{1}\left(\widetilde{Z}_{i}\right)$ so that $\left(\tilde{z}_{i}, d_{i}\right) \in \gamma_{i}\left(\widetilde{Z}_{i}\right)$, if and only if $\tilde{z}_{i} \in \gamma_{i}^{0}\left(\widetilde{Z}_{i}\right)$ and $d_{i} \in \gamma_{i}^{1}\left(\widetilde{Z}_{i}\right)$. Define, for $i \in F, T_{i}\left(\widetilde{Z}_{i}, d\right)=F_{i}\left(\gamma_{i}^{0}\left(\widetilde{Z}_{i}\right), \widetilde{Z}_{i}\right)$. Thus $T_{i}$ represents the actual trades after maximization. By Lemma $6, T_{i}\left(\widetilde{Z}_{i}, d\right)$ is a singleton.

For $i \in H$, define $T_{i}\left(\widetilde{Z}_{i}, d\right) \equiv F_{i}\left(\gamma_{i}\left(\widetilde{Z}_{i}, d\right), \widetilde{Z}_{i}\right)$. Again, these are the actual trades an agent intends to carry out, conditional upon $\left(\widetilde{Z}_{i}, d\right)$ and, again by Lemma $6, T_{i}\left(\tilde{Z}_{i}, d\right)$ is a singleton.

Define $T(\widetilde{Z}, d)=\left(T_{1}\left(\widetilde{Z}_{1}, d\right), \ldots, T_{m}\left(\widetilde{Z}_{m}, d\right), \gamma^{1}(\widetilde{Z})\right)$ where $\gamma^{1}(\widetilde{Z})=\left(\gamma_{i}^{1}\left(\widetilde{Z}_{i}\right)\right)_{i \in F}$. Let $\varepsilon \equiv \varepsilon_{1}=\varepsilon_{2}$ and define $K^{\varepsilon}=K^{\varepsilon_{1}, \varepsilon_{2}}$. Let $D$ be a bounded and closed hypercube of nonnegative dividend vectors $d$. We will show that $T$ is a function from $K^{\varepsilon} \times D$ to $K^{\varepsilon} \times D$. Clearly, $T_{i}\left(\widetilde{Z}_{i}, d\right) \in K_{i}$ since, by assumption, $F_{i}\left(\gamma_{i}\left(\widetilde{Z}_{i}, d\right), \widetilde{Z}_{i}\right) \in B_{i}(d) \subset K_{i}$ for $i \in H$ and $F_{i}\left(\gamma_{i}^{0}\left(\widetilde{Z}_{i}\right), \widetilde{Z}_{i}\right) \in B_{i}(d) \subset K_{i}$ for $i \in F$. Moreover, for $\widetilde{Z} \in K^{\varepsilon}, T_{i}\left(\widetilde{Z}_{i}, d\right) \in K_{i}^{\varepsilon}$ for $i=i_{1}$, or 
$i=i_{2}$, since $\tilde{z}_{i_{1} j} \leqq-\varepsilon$ and $\tilde{z}_{i_{2} j} \geqq \varepsilon$ implies $\tilde{z}_{i_{1} j}=z_{i_{1} j}$ and $\tilde{z}_{i_{2} j}=z_{i_{2} j}$ by Assumptions T.1 and T.2. Finally, $\gamma^{1}(\tilde{Z})$ is an element of $D$, for by Lemma $6 \gamma^{1}(\tilde{Z}, d)$ is a singleton. We may choose upper bounds $\bar{d}_{i}$ for the components of $D$ so that $\gamma_{i}^{1}\left(\tilde{Z}_{i}\right) \leqq \bar{d}_{i}$ for all $\tilde{Z}$ in the compact set $K$. Thus $D$ can be chosen compact while preserving $\gamma^{1}(\overline{\widetilde{Z}}) \in D$.

Next we show that $T(\tilde{Z}, d)$ is a continuous function. We know that $\gamma_{i}\left(\widetilde{Z}_{i}, d\right)$ (for $i \in H)$ and $\gamma_{i}\left(\widetilde{Z}_{i}\right)$ (for $i \in F$ ) are upper hemi-continuous and $F(\tilde{Z})$ is continuous. Since $T_{i}\left(\widetilde{Z}_{i}, d\right)$ is a composite of $F_{i}$ and $\gamma_{i}$ for $i \in H \cup F$, it is upper hemi-continuous. But it is also a function, so it must be a continuous function (see Berge for the relevant theorems). Since $\gamma_{i}^{1}\left(\widetilde{Z}_{i}\right)$ is also a continuous function, $T(\widetilde{Z}, d)$ is continuous. Hence, Brouwer's Fixedpoint Theorem guarantees the existence of $\left(Z^{*}, d^{*}\right)$ such that $\left(Z^{*}, d^{*}\right)=T\left(Z^{*}, d^{*}\right)$. But this means that $\left(Z^{*}, d^{*}\right)$ is a strong equilibrium. It is non-trivial since $Z^{*} \in K^{\varepsilon}$.

\section{APPENDIX}

Debreu's Social Equilibrium Existence Theorem (Modified). Let $A_{i}$ be a compact convex set in $R^{n}$ for $i=1, \ldots, m$. Define $\bar{A}_{i}=A_{1} \times \ldots \times A_{i-1} \times A_{i+1} \times \ldots \times A_{m}$ and let $\bar{a}_{i}$ denote an element of $\bar{A}_{i}$. Suppose that $S_{i}\left(\bar{a}_{i}\right)$ is a correspondence from $\bar{A}_{i}$ whose values are subsets of $A_{i}$. Suppose $S_{i}$ has a closed graph $G_{i}$, and let $V_{i}\left(a_{i}, \bar{a}_{i}\right)$ be a continuous realvalued function defined on $G_{i}$ such that $\phi_{i}\left(\bar{a}_{i}\right)=\max _{a_{i} \in S_{i}\left(\bar{a}_{i}\right)} V_{i}\left(a_{i}, \bar{a}_{i}\right)$ is continuous. If for all $i$ and $\bar{a}_{i}$, the set $M_{i}\left(\bar{a}_{i}\right)=\left\{a_{i} \in S_{i}\left(\bar{a}_{i}\right) \mid V_{i}\left(a_{i}, \bar{a}_{i}\right)=\phi_{i}\left(\bar{a}_{i}\right)\right\}$ is contractible, then there exists an equilibrium.

Remark 1. The vector $\left(a_{1}^{*}, a_{2}^{*}, \ldots, a_{m}^{*}\right)$ is called an equilibrium if for all $i$, $a_{i}^{*} \in M_{i}\left(\dot{a}_{i}^{*}\right)$.

Remark 2. The set $A$ is said to be contractible if it is continuously deformable to a point $a_{0} \in A$, i.e. there exists a continuous function $H(t, a)$ from $[0,1] \times A$ into $A$ such that $H(0, a)=a_{0}$ and $H(1, a)=a$. Clearly a convex set is contractible (let $\left.H(t, a)=t a+(1-t) a_{0}\right)$.

First version received September 1976; final version accepted November 1978 (Eds.).

This work was supported in part by National Science Foundation Grant SOC74-11446 at the Institute for Mathematical Studies in the Social Sciences at Stanford University, in part by NSF Grant GS41494, and in part by a UC Davis Intercampus Research Grant. R. Starr gratefully acknowledges the hospitality of the Group for the Application of Mathematics and Statistics to Economics, UC Berkeley and the support of John Simon Guggenheim Fellowship. We are much indebted to Douglas Gale and Peter Hammond for significant improvements over earlier versions. We would also like to thank Vincent Crawford, Richard Schmalensee, David Starrett and the participants in the 1975 Stanford Summer Seminar for comments.

\section{NOTES}

1. Böhm-Lévine (1979) and Gale (1979) have studied unemployment with relatively complete information in different models.

2. Information is said to be " myopic" in the sense that the informational structure is non-cooperative. The agents are ignorant of the desires and possibilities of other agents. In particular, agents do not foresee changes in others' actions. We accept the presumption that agents cannot profitably form coalitions to overturn a non-cooperative equilibrium with unemployment. For example, unemployed auto workers, even if they collectively possessed the expertise, could not combine to produce cars that would be sold in their entirety since the new income generated by the coalition would not be spent entirely on cars. Generally speaking, a coalition consisting of all rationed agents would have to cooperate in order to overcome an unemployment equilibrium.

3. For vectors, " $\gg$ " means strict inequality in every component, " $>$ " means strict inequality in some components with weak inequality in all other components, and " $\geqq$ " means weak inequality in every component.

4. Assume both $\tilde{z}_{i}^{1}, \tilde{z}_{i}^{2}$ belong to $B_{i}$, and $z_{i}^{1}, z_{i}^{2}$ are optimal. Claim: we can find a $\tilde{z}_{i}^{\theta} \in B_{i}$ such that the convex combination $\theta z_{i}^{1}+(1-\theta) z_{i}^{2}=F_{i}\left(\tilde{z}_{i}^{\theta}, Z_{i}\right)$. Suppose agent $i$ is not rationed on any buying offer for both $\tilde{z}_{i}^{1}$ and $\tilde{z}_{i}^{2}$, then $F_{i j}\left(\theta \tilde{z}_{i}^{1}+(1-\theta) \tilde{z}_{i}^{2}, \tilde{Z}_{i}\right)=\theta \tilde{z}_{i j}^{1}+(1-\theta) \tilde{z}_{i j}^{2}$ for $j$ such that $\tilde{z}_{i j}^{1}$ and $\tilde{z}_{i j}^{2}$ 
are both non-negative. For $j$ such that $\tilde{z}_{i j}^{1}$ and $\tilde{z}_{i j}^{2}$ are both negative, we have, by one-sidedness $\left[0 \geqq F_{i j}\left(\tilde{z}_{i}, \tilde{Z}_{i}\right) \geqq \tilde{z}_{i j}\right.$ if $\left.\tilde{z}_{i j}<0\right], \tilde{z}_{i j}^{\theta} \leqq F_{i j}\left(\tilde{z}_{i}^{\theta}, \tilde{Z}_{i}\right) \leqq \theta z_{i j}^{1}+(1-\theta) z_{i j}^{2}$. Thus

$$
p \tilde{z}_{i} \leqq p\left(\theta z^{1}+(1-\theta) z^{2}\right) \leqq \theta\left(\bar{M}_{i}-M_{i}^{1}\right)+(1-\theta)\left(\bar{M}_{i}-M_{i}^{2}\right) \leqq \bar{M}_{i}+\left[\theta M_{i}^{1}+(1-\theta) M_{i}^{2}\right] \geqq 0 .
$$

Hence $\tilde{z}_{i}^{\theta} \in B_{i}$. Thus $\theta z^{1}+(1-\theta) z^{2}$ is possible and so, if utility functions are strictly quasi-concave, we know by usual arguments that there are demand functions rather than correspondences.

5. A similar statement could be concocted if one or both of $i_{1}, i_{2}$ are firms.

6. Again we do not need to assume that households actually know what the other offers are in fact. We only suppose that each agent knows the consequences of his actions under the presumption that other agents do not alter their current actions.

\section{REFERENCES}

ARROW, K. J. (1959), “ Toward a Theory of Price Adjustment ”, in Abramovitz, M. et al. The Allocation of Economic Resources (Stanford University Press).

ARROW, K. J. and HAHN, F. H. (1971) General Competitive Analysis (Holden-Day).

BENASSY, J. P. (1975), “Neo-Keynesian Disequilibrium Theory in a Monetary Economy", Review of Economic Studies, 42 (4).

BERGE, C. (1963) Topological Spaces (Macmillan).

BÖHM, V. and LÉVINE, P. (1979), "Temporary Equilibria with Quantity Rationing", Review of Economic Studies, (this issue).

CLOWER, R. (1965), "The Keynesian Counterrevolution: A Theoretical Appraisal ", in Hahn, F. H. and Brechling, F. P. R. (eds.) The Theory of Interest Rates (Macmillan).

$\rightarrow$ DEBREU, G. (1952), “A Social Equilibrium Existence Theorem ", Proceedings of the National Academy of Sciences, 38 (10), 886-893.

DRĖZE, J. H. (1975), "Existence of an Equilibrium under Price Rigidities", International Economic Review, 16 (2).

GALE, D. (1979), " Large Economies with Trading Uncertainty ”, Review of Economic Studies, (this issue).

GLUSTOFF, E. (1968), "On the Existence of a Keynesian Equilibria ", Review of Economic Studies, 35 (3).

GRANDMONT, J. M. (1974), “ On the Short-Run Equilibrium in a Monetary Economy ”, in Drèze, J. H. (ed.) Allocation Under Uncertainty, Equilibrium and Optimality.

GRANDMONT, J. M. and LAROQUE, G. (1976), "On Temporary Keynesian Equilibria ", Review of Economic Studies, 43 (1).

HAHN, F. (1978), "On Non-Walrasian Equilibria ", Review of Economic Studies, 45, 1-18.

HAHN, F. and NEGISHI, T. (1962), "A Theorem on Non-Tâtonnement Stability ”, Econometrica, 30, 463-469.

HELLER, W. P. (1978), "Continuity in General Nonconvex Economies (with Application to the Convex Case", Equilibrium and Disequilibrium in Economic Theory, ed. G. Schwödiauer, Reidel, 27-38. 